\title{
Employee-level open innovation in emerging markets: linking internal, external, and managerial resources
}

\author{
Yuosre F. Badir $^{1}$ - Björn Frank ${ }^{2}$ - Marcel Bogers ${ }^{3,4}$
}

Received: 3 September 2018 / Accepted: 27 June 2019 / Published online: 9 August 2019

(C) The Author(s) 2019

\begin{abstract}
Leveraging external sources of knowledge has become a vital element of innovation strategy, especially in emerging markets, where many firms lack the sophisticated knowledge required to innovate. However, extant research in this domain puts little emphasis on emerging economies and also typically treats openness as a firm-level concept. In contrast, this study investigates how individual employees rely on both internal and external knowledge to increase their innovative work output (and, secondarily, their customer acquisition performance) and how their supervising manager's characteristics moderate these mechanisms. Using hierarchical linear modeling of data collected from 123 employees and 50 managers in telecommunications companies in the emerging market of Vietnam, we find support for our hypothesized relationships. These findings have important implications for research and practice as they highlight the role of the individual employee in open innovation, the need for considering a more distributed set of organizational functions, and the relevance for emerging markets.
\end{abstract}

Keywords Open innovation · Microfoundations $\cdot$ External knowledge sources $\cdot$ Managerial resources $\cdot$ Emerging markets · Customer acquisition

\section{Introduction}

Innovation is important for enhancing customer value and, consequently, customer equity and competitive advantage, as

Rajendra Srivastava and V. Kumar served as Special Issue Guest Editors for this article.

Björn Frank

frank@waseda.jp

Yuosre F. Badir

badir@ait.asia

Marcel Bogers

marcel@ifro.ku.dk

1 School of Management, Asian Institute of Technology, Khlong Luang District, Pathumthani 12120, Thailand

2 Faculty of Commerce, Waseda University, 1-6-1 Nishi-Waseda, Shinjuku-ku, Tokyo 169-8050, Japan

3 Department of Food and Resource Economics, University of Copenhagen, Rolighedsvej 25, 1958 Frederiksberg C, Denmark

4 Garwood Center for Corporate Innovation, University of California, F402 Haas School of Business, \#1930, Berkeley, CA 94720-1930, USA recognized by marketing theories such as the return on marketing/quality models (Rust et al. 1995, 2004), the customer value-based theory of the firm (Slater 1997), and other marketing adaptations of resource-based theory (Kozlenkova et al. 2014). Product innovation drives customer value via quality and functionality (Frank et al. 2014b; Slater 1997; Woodruff 1997), whereas process innovation drives customer value via operational efficiency and thus lower prices (Woodruff 1997; Wimalachandra et al. 2014a), via manufacturing quality (Wimalachandra et al. 2014b), and via flexibility and thus responsiveness to customers (Blocker et al. 2011; Wimalachandra et al. 2014a).

Firms in emergent markets still tend to lack advanced knowledge and capabilities (Bogers et al. 2019; Fu et al. 2014), which limits their opportunities for innovation and customer value creation (Frank and Enkawa 2008). Consequently, research on emerging market firms has emphasized, but not yet shown empirically, the importance of drawing on external knowledge sources to strengthen their internal innovation processes (Guerrero and Urbano 2017; Hertenstein and Williamson 2018). Such processes are discussed in the literature on open innovation, defined as "a distributed innovation process that involves purposively managed knowledge flows across the organizational boundary" (Chesbrough and 
Bogers 2014, p. 17). Theoretically, it is unclear whether assumptions and findings in the open innovation literature are equally valid in emerging market firms, which do not have the same capabilities as firms in developed markets (Fu et al. 2014), leaving managers without advice on how to implement an open innovation strategy.

Despite the importance of building emerging market firms' own capabilities to enable them to catch up with firms in developed markets (Landini and Malerba 2017; Malerba and Mani 2009), the paradoxical lack of investment in, and outcome of, their innovation capabilities can be directly linked to a negligence of human capital factors, including firm managerial capabilities (Cirera and Maloney 2017). Accordingly, any attempt to promote open innovation in emerging economies should consider the role of individual employees and managers. Therefore, we investigate how the placement of managers with certain characteristics in emerging market firms helps subordinate employees to leverage the use of internal and external knowledge sources into innovative work output (IWO). To account for employees' difficulties in allocating their time efficiently across the multitude of highly diverse external sources, we follow the well-established distinction between external search breadth (broad search even if shallow) and depth (indepth exploitation of a source, despite less time for consulting other sources) (Laursen and Salter 2006, 2014).

To examine how internal knowledge, external knowledge, and managerial facilitation promote IWO in emerging market firms, we develop hypotheses on the main effects, and their curvilinear nature, of employee use of internal (H1) and external (H2-H3) knowledge sources on IWO, and on the moderating effects of the supervising manager's technical competence (H4-H5) and experience (H6). We test these effects with nested data from 123 employees and their managers within 50 telecommunications firms in the emerging market of Vietnam. Using meta-analysis, we then compare our results for emerging market firms with other studies on developed market firms and thus contribute to an understanding of the characteristic attributes of open innovation in emerging markets. As an extension of our research on employee-level open innovation processes distributed across functional areas of the firm, we also explore how employees leverage internal and external knowledge sources in customer acquisition processes.

Our study builds new knowledge on the key levers of innovation capacity building in emerging market firms, showing firms how their employees can leverage internal and external knowledge differentially into IWO and how selecting managers with certain characteristics can facilitate this process. In addition, our study contributes more broadly to the literature on open innovation by being the first to address the managerial role in facilitating open innovation processes, by testing the debated complementarity between internal and external knowledge sources (Cassiman and Veugelers 2006; Cohen and Levinthal 1990; West and Bogers 2014), the first to compare the roles of internal and external knowledge sources on employee contributions to product versus process innovation, and the first to explore, in an analogous manner, the roles of internal and external knowledge sources and managerial facilitation in the marketing context of customer acquisition processes. Our discussion provides a detailed overview of these and other contributions.

\section{Theory and hypotheses}

Drawing on the literature on open innovation, knowledge search behavior, and leadership, we present a model of individual-level knowledge sourcing and innovation performance, combined with the moderating role that direct managers play in this relationship (see Fig. 1).

\section{Openness for innovation: from the organizational level to the individual level}

Several decades of research have revealed that firm-external resources can contribute to a firm's innovation performance (Randhawa et al. 2016; West and Bogers 2014). The early research by von Hippel (1988), for instance, emphasizes the importance of users as a source of innovation (Bogers et al. 2010). Further sources of innovation include suppliers, competitors, universities, and other complementors (Chesbrough and Bogers 2014; Laursen and Salter 2006). Building on a longer tradition in research on absorptive capacity (Cohen and Levinthal 1990) and "not invented here" (Katz and Allen 1982), recent research reports that firm-internal resources (knowledge, structures, and processes) help the firm to integrate knowledge from external sources (Faems et al. 2010; West and Bogers 2014) and to use it for innovation (Foss et al. 2011). This complementarity of internal and external knowledge implies that balancing them leads to improved innovation performance (Cassiman and Veugelers 2006). Despite our conceptual focus on openness to external sources, our study thus considers the performance impact of both internal and external sources of innovation.

While the innovation impact of external knowledge sources has been well documented at the level of organizations (Du et al. 2014), the innovation impact of individual employees' openness has not received much attention (Ettlie and Elsenbach 2007). This lack of understanding of openness at the level of employees may partially explain why many organizations have failed to benefit from adopting an open innovation strategy (Salter et al. 2014). Nevertheless, the employee level of analysis is crucial because an organization's external search is fundamentally embedded in the cognitive abilities and knowledge base of individual employees (Cohen and Levinthal 1990; Felin et al. 2015). Specifically, organizations acquire and create knowledge through individuals who 
Fig. 1 Conceptual framework and hypotheses

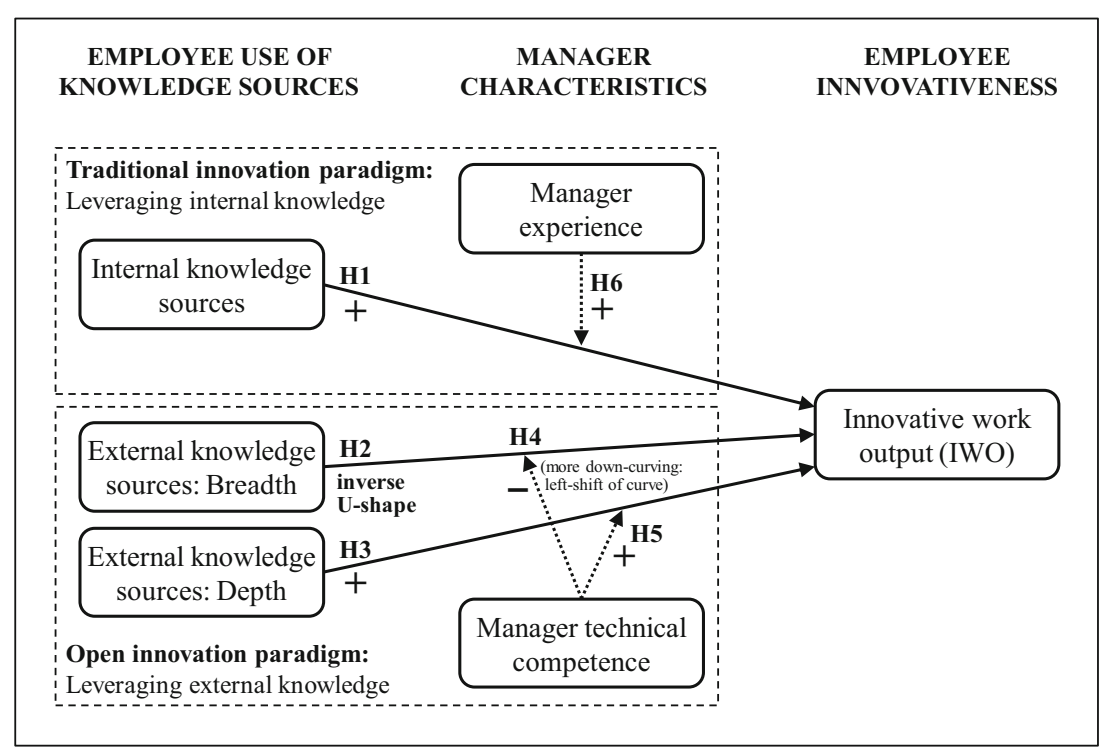

provide the foundation for organizational knowledge, creativity, and innovation (Amabile 1988; Salter et al. 2015). Moreover, due to the transience of competitive advantages in dynamic environments, employees are the most important source of sustainable competitive advantage for technologyintensive organizations (Black and Synan 1997). In this context, employees can help improve business performance through their abilities to acquire knowledge, to generate ideas and solutions, and to use these as building blocks for new and better products, services, and work processes (de Jong and den Hartog 2010).

\section{Openness for innovation in emerging markets}

More recently, a limited but growing body of research has started to explore the importance of external knowledge sources for developing a firm's innovation capability in emerging markets (Guerrero and Urbano 2017; Hertenstein and Williamson 2018). The role of open innovation has been explained both as being problematic, due to the inherent characteristics of such countries, and as constituting an opportunity, due to the comparatively limited knowledge within emerging market firms (Bogers et al. 2019; Fu et al. 2014). While some studies report on governmental efforts to promote stakeholder linkages to spur open innovation in certain emerging economies (Fu et al. 2014; Guerrero and Urbano 2017), there is still a lack of understanding regarding the characteristic attributes of open innovation in emerging markets. Some hints have been provided by conceptual research that highlights the role of culture in determining preferences for certain knowledge types in the cross-border transfer of organizational knowledge (Bhagat et al. 2002) and that considers the interplay between internal and contextual factors in innovation management (Nagano et al. 2014). Still, the overall understanding of the characteristics of open innovation in emerging markets remains limited, and our study aims to address this gap.

\section{Employee innovativeness: innovative work output (IWO)}

The literature on individual employees' IWO tends to focus on measures such as patents' quantity, novelty, and quality (Dahlander et al. 2016), which are limited to tasks fully dedicated to innovation, as is the case with R\&D employees (de Jong and Den Hartog 2010). However, innovation may take place across all employees (Axtell et al. 2000; Dorenbosch et al. 2005), not least in technology-intensive industries, where the environment is dynamic, competitive and fastchanging (Shih and Susanto 2011) and work activities tend to be non-standardized, non-routine, and complex (Zhang and Bartol 2010). In such work contexts, employees need to go beyond established routines and develop and implement new ideas, methods, approaches, or procedures (Shih and Susanto 2011), which translate into IWO (Van Minh et al. 2017).

We view innovation as a process that involves both the generation of new ideas, practices, or artifacts (i.e., creativity) and their implementation within organizations (Axtell et al. 2000; Van Minh et al. 2017). Creativity, which refers to the development of ideas that are both novel and useful to the firm (Woodman et al. 1993), is the first phase of an innovation process (Baer 2012). Idea implementation, on the other hand, describes the process of converting ideas into new (radical) or improved (incremental) products, services, or ways of doing things (Baer 2012; Woodman et al. 1993). The idea generation and implementation phases are interrelated since the 
implementation of ideas requires finding ideas in the first place (Parzefall et al. 2008). The view of innovation as an integrated process involving both the suggestion and implementation of ideas has been explored at different organizational levels in the literature (Mumford and Gustafson 1988).

In line with this view, an employee's IWO in this research encompasses both the generation and implementation of ideas (de Jong and Den Hartog 2010). Therefore, we define the employee's IWO as the frequency of producing ideas (e.g., improving products, services, and/or work practices) and implementing, or contributing to the implementation of, these ideas (e.g., developing new products or services and/or optimizing the work process). Innovative employees may engage in either one, or a combination, of these two dimensions at any time (Van Minh et al. 2017).

\section{The effect of employee use of internal knowledge sources on IWO}

Employees frequently deal with problems and challenges at work by seeking knowledge from sources internal to the organization, such as colleagues, managers, and subordinates. Benefits of seeking knowledge from internal, rather than external, sources include lower search cost, higher accessibility, and lower transfer time (Anderson et al. 2001). We argue that acquiring knowledge from internal sources can improve an employee's IWO for three reasons.

First, internal knowledge (e.g., information, ideas, and solutions) comes from other employees within the same organization who know the organization's goals, available resources, and work processes. Therefore, the knowledge is probably specific to the problem or challenge, thereby facilitating its use, integration, and implementation (Dougherty 1992). Second, knowledge from internal sources may have been used before in other departments, functions, or projects within the organization, which means it is probably relatively familiar to the employee, thereby facilitating understanding (Menon and Pfeffer 2003). Even if the internal knowledge happens to be unfamiliar to the employee, greater accessibility of internal knowledge sources facilitates communication with the source, making it easier to understand the knowledge (Menon and Pfeffer 2003). Better communication with the internal source also makes it easier for the employee to internalize the knowledge and combine it with previously held knowledge, which facilitates the development of new ideas and their implementation (Woodman et al. 1993). Third, knowledge from internal sources tends to be familiar to the firm's other employees. Therefore, its implementation by the employee is expected to face less resistance (Antons and Piller 2015).

H1: Employee use of internal knowledge sources has a positive effect on IWO.

\section{The effects of employee use of external knowledge sources on IWO}

In open innovation, employees, with support from the organization (especially their direct managers), play the main role in interacting with external sources (Salter et al. 2015) either by bringing knowledge into the organization (inbound open innovation) or transferring knowledge outside (outbound open innovation) (Enkel et al. 2009). In this study, we focus on inbound open innovation and examine the innovation performance impact of individual employees' openness (West and Bogers 2014). In contrast to the use of internal knowledge, where the extant literature has typically focused on the generic, overall relationship with IWO, the open innovation literature differentiates between two types of external knowledge search with potentially different impacts on innovation performance: external search breadth and external search depth (Laursen and Salter 2006). Because this distinction is very well established in the literature, we also examine the respective roles of breadth and depth in employee use of external knowledge sources in driving IWO.

Breadth of employee use of external knowledge sources External search breadth refers to the number of distinct external knowledge sources from which a firm or an employee seeks at least a moderate, but not necessarily high, degree of knowledge (Laursen and Salter 2006). It helps enrich the pool of solutions available to solve innovation challenges endemic to the firm (Dahlander et al. 2016). At the employee level, Salter et al. (2015) assert that there is an inverted U-shape relationship between search breadth of R\&D employees and idea generation. Below an optimum value of search breadth, employees drawing on ideas from additional external sources gain access to more knowledge, which means they can generate a broader range of useful ideas for their firms. However, searching beyond an optimum value of search breadth results in disadvantages in the form of higher costs of knowledge integration and coordination. In line with this view, Dahlander et al. (2016) state that using a range of knowledge sources that is too broad may result in the employee being unable to screen, process, or act upon the new knowledge or effectively integrate it into the firm's existing knowledge base.

IWO may also be connected to idea implementation in nonR\&D settings, considering the distribution of innovative behaviors within high-tech firms (similar to the diffusion of product orientation examined by Lam et al. 2010), even in emerging markets (Deshpandé and Farley 2004). We presume that an inverted U-shape with a decreasing component is even more likely in our context of IWO by general technical employees, rather than only R\&D employees, for two reasons. First, the combination of idea generation and implementation is more complex, more costly to implement, and is composed 
of more tacit knowledge than solely idea generation (Carmeli et al. 2006). Second, IWO in non-R\&D settings is less structured. Especially in high-tech industries, technical challenges rarely have obvious solutions. Instead, they are difficult to identify and have to be discussed frequently with knowledge sources (Henriksen 2001).

Therefore, below an optimal degree of search breadth, employees facing work challenges may benefit from seeking knowledge across multiple external sources. A higher number of consulted sources leads to exposure to more knowledge, which facilitates idea generation and implementation and probably has a beneficial effect on the employee's IWO. However, searching beyond an optimal degree of search breadth may decrease an employee's IWO because of the complexity of the process and because it consumes an employee's limited time and attention (Dahlander et al. 2016). Indeed, a very broad use of external knowledge sources tends to result in their shallow exploitation and may unearth knowledge that does not match with the firm's current knowledge base (Allen 1966), resulting in confusion and misunderstandings between the employee and colleagues, which does not help in implementing the ideas. In addition, we expect that searching beyond the optimum incurs higher marginal costs (e.g., cost of communication, interaction, coordination) than benefits (Salge et al. 2013). Moreover, attempts to implement external ideas and solutions usually faces resistance from colleagues in what is known as "not-invented-here syndrome", which involves a negative attitude toward knowledge (i.e., ideas, solutions, and technologies) derived from external sources (Antons and Piller 2015). Given individuals' limited capacity to absorb external knowledge (Cohen and Levinthal 1990), at some point, searching for external knowledge will result in diminishing returns in terms of innovation output, similar to the effect that Laursen and Salter (2006) argue for at the firm level. Finally, to implement externally acquired solutions and ideas, an employee first needs to persuade colleagues of their merits. Bringing more diverse external ideas into the firm leads to greater discussion and resistance and, consequently, consumes more of the employee's time and effort, resulting in delays and lower likelihood of implementation.

H2: Breadth of employee use of external knowledge sources has an inverted U-shaped effect on IWO such that medium breadth maximizes IWO, whereas low and high breadth lead to lower IWO.

Depth of employee use of external knowledge sources Also called external search depth, depth of employee use of eternal knowledge sources refers to the number of distinct external knowledge sources from which a firm or an employee seeks a particularly high, rather than moderate (as in case of breadth), degree of knowledge (Laursen and Salter 2006). The extant research on external search depth has focused almost exclusively on the firm level and has produced mixed results on the effect of a firm's external search depth and innovation performance. For instance, Laursen and Salter (2006) report an inverted-U shape relationship between external search depth and the firm's product innovation, whereas Terjesen and Patel (2017) find a positive linear relationship between external search depth and process innovation.

Within our focus on the employee level of analysis, we posit that more external knowledge broadens the pool of knowledge that an employee can leverage into idea generation and implementation (Dahlander et al. 2016), thereby positively influencing IWO. In contrast to our arguments on the drawbacks of high external search breadth (H2), we argue below that external search depth influences IWO positively even at high levels.

Research shows that an effective transfer of complex knowledge needed to generate and implement novel ideas at work demands that employees allocate sufficient time to the knowledge source (Hansen 1999) in order to determine whether and how ideas can be implemented in their own work context (Murray and O'Mahony 2007). Moreover, external search depth involves frequent interaction between the employee and the source, which is likely to promote and enhance reciprocity, communication, and trust, thus facilitating the acquisition of sensitive information and tacit knowledge (Badir and O'Connor 2015), which are important for enhancing an employee's IWO.

H3: Depth of employee use of external knowledge sources has a positive effect on IWO.

\section{The moderating role of manager characteristics: technical competence and experience}

While formal power describes a manager's influence over subordinate employees emerging from hierarchical or legitimate authority, corresponding to responsibility and discretion over a range of resources (Tushman and Romanelli 1983), its legitimacy is a function of the hierarchical system itself and is stable over time (Aime et al. 2014). The formal position enables a manager to access internal and external sources of information (Tushman 1977) and to influence innovation strongly (Ibarra 1993; van de Ven 1986). However, formal authority is not the only form of power in an organization (Aime et al. 2014); informal power stems from individual attributes such as experience and technical competence (Ibarra 1993). According to the literature on an individual's sources of power in an organization, both formal and informal power influence outcomes together (Astley and Sachdeva 1984; Ibarra 1993). Based on this theory, we examine the combined effect of a manager's formal and informal power on the relationship between a subordinate employees' knowledge search and IWO. 
In high-tech organizations, individuals with higher technical competence and experience are more likely to be promoted to managerial positions (Van Minh et al. 2017). In a study on technical professions, Maxwell (1989) finds that technical employees tend to become technical managers if they have technical competences, past experience, or have spent time at the company. These resources are considered the basic managerial competencies needed by managers in high-tech organizations (Schroder 1989). In this article, we consider an individual's length of service at the firm as a top manager and technical competence as sources of informal power and examine how they affect the relationship between subordinate employees' knowledge search and IWO. Technical competence is understood as excellent technical skills and broad knowledge, which fosters a manager's ability to perform work duties (Van Minh et al. 2017). Managers are considered technically competent when they have up-to-date technical knowledge, an understanding of recent technologies (Grant et al. 1997), and are able to perform technical duties, answer technical questions, suggest technical solutions, and apply knowledge to problems (Hysong 2008).

Representing the technological gatekeepers in Allen's seminal research (Allen 1977), managers are expected to update the organization's knowledge through external ties. More technically competent managers are more likely to be aware of external knowledge and technical developments. When subordinate employees turn to them for technical advice, technically competent managers likely refer these employees to external sources and, subsequently, help them to implement their innovative ideas. While their formal position gives these managers access to both internal and external knowledge sources (Tushman 1977), we assume that they still recommend external sources because their organization's internal knowledge tends to be more limited and less updated in comparison. Hence, we predict manager technical competence to play a major role in helping subordinate employees leverage the use of external knowledge sources, both breadth and depth, into IWO. In contrast, managers with longer experience in their current top management position in the organization will play a more prominent role in helping subordinate employees leverage the use of internal knowledge sources into IWO. Such manager experience implies the accumulation of, and familiarity with, organization-specific knowledge and skills and reflects how often these managers have repeated similar tasks. This type of routinization and familiarity makes managers highly efficient and effective in repeating the same tasks within the firm using the same knowledge (Safdar et al. 2017). However, given that external knowledge is not always easy to understand or integrate into an existing body of knowledge (Vega-Jurado et al. 2008) and a manager's flexibility declines over time (O'Connell et al. 2008), we posit that it is unlikely that manager experience plays a major role in helping subordinate employees leverage the use of external knowledge sources into IWO.

Manager technical competence: limiting the benefits of breadth of external knowledge source use $\mathrm{H} 2$ states that there is an optimum external search breadth, which maximizes IWO. Both higher and lower external search breadth leads to lower IWO. We posit that higher manager technical competence negatively shifts this optimum point such that lower external search breadth maximizes IWO. That is, we predict that a subordinate employee of a manager with high technical competence needs lower external search breadth to maximize IWO, whereas a subordinate employee of a manager with low technical competence needs higher external search breadth to maximize IWO.

As stated in $\mathrm{H} 2$, using a range of external knowledge sources that is too wide may result in disadvantages in the form of higher costs of knowledge integration and coordination. In addition, given the limited time and attention that can be dedicated to each knowledge source within a wide range of sources (Dahlander et al. 2016), employees might become unable to understand, assimilate, and act upon the highly diverse new knowledge and unable to effectively integrate it into the firm's existing knowledge base. We suggest that high technical competence of the manager focuses, and thereby enhances the effectiveness of, the employee's external search for knowledge such that the employee can maximize IWO with lower, but wisely-selected, external search breadth. Technically competent managers are aware of the latest knowledge outside the organization and of where it exists and, upon identification of such knowledge, may have access to this knowledge due to their formal position. Hence, they are in a good position to direct subordinate employees to the right knowledge source and to give them access to this knowledge. Thus, the employee can acquire the needed knowledge through fewer external sources, which enhances the time and attention available to each of the fewer sources and helps leverage this knowledge into IWO.

Moreover, once the employee acquires the needed knowledge, a more technically competent manager may help the employee to implement the proposed solutions and ideas obtained from recommended external sources, thus maximizing IWO with lower search breadth. First, the manager's technical competence makes it likely that the knowledge from the recommended external sources relates more to the employee's work problem and better fits the firm's internal knowledge stock. Second, it requires less effort for the employee to convince the technically competent manager of the merits of acquired external knowledge because the manager more easily understands it and because the manager is more familiar with recommended sources, which facilitates and accelerates implementation. 
On the other hand, an employee under the supervision of a manager with low technical competence may need to engage in a broader external search to maximize IWO as the manager cannot direct the employee to the right knowledge sources or help evaluate the benefits and drawbacks of any potential external solutions (Howell 2005). In this case, the employee's search for external knowledge will be subject to uncertainty (Laursen and Salter 2006) and identifying and then implementing any creative solutions will demand much more time and effort.

H4: The optimal breadth of employee use of external knowledge sources, which maximizes IWO, is lower when the supervising manager's technical competence is higher. Thus, as manager technical competence increases, the inverse U-shaped effect of breadth on IWO is shifted to the left.

Manager technical competence: enhancing the benefits of depth of external knowledge source use We posit that a manager's technical competence positively moderates the effect of a subordinate employee's depth of external knowledge sources use on IWO. A manager with high technical competence helps subordinate employees through skillful selection of important and complex, but solvable, problems (Van Minh et al. 2017). Once a problem has been identified, employees search for knowledge to solve the problem. In this situation, a technically competent manager may support an employee in two ways.

First, based on advanced technical knowledge and awareness of up-to-date external knowledge sources, the manager may recommend and facilitate access to external sources with superior knowledge (Van Minh et al. 2017), making the employee's search for innovative solutions and their exploitation more effective, thus translating external search depth into higher IWO.

Second, deep use of external knowledge sources brings in knowledge that, for the firm, is complex and distinct, which means it is more difficult to understand and implement (Laursen and Salter 2006). However, a manager with high technical competence can understand and conceive ways of implementing the knowledge more quickly (Howell 2005), and can thereby help the employee to translate the deep knowledge into IWO.

H5: As the technical competence of the supervising manager increases, the effect of depth of employee use of external knowledge sources on IWO is strengthened.

\section{Manager experience: enhancing the benefits of using internal} knowledge sources We suggest that managers with longer experience working for an organization can enhance the effect of an employee's use of internal knowledge sources on IWO.
First, managers with longer experience are likely to be more aware of, and have better access to, the knowledge that exists in the organization. Furthermore, they are also more likely to have experience in translating this knowledge into innovation (Hannah and Lester 2009; Tushman 1977). Hence, we posit that experienced managers are more capable of guiding employees towards, and facilitating access to, the right knowledge from internal sources, thereby making the search for internal knowledge more effective in stimulating IWO.

Second, we posit that managers with longer experience in the organization are in a better position to provide their employees with internal resources that help them to implement ideas. Previous research in organization innovation suggests that information, material resources, and support must be acquired and invested in order for a new idea to be approved or tolerated and implemented (Kanter 1988). More experienced managers tend to be better at navigating an organization's political waters, gaining access to needed resources, and getting things done (Ibarra 1993). They can use their power and influence to persuade others of the relative merits of solutions and improvements derived by the employee from internal knowledge sources, mobilize information, material resources, and support, and overcome resistance to change (Ibarra 1993).

H6: As the duration of manager experience in the organization increases, the effect of employee use of internal knowledge sources on IWO is strengthened.

\section{Methodology}

\section{Questionnaire development}

To test our hypotheses, we developed two questionnaires. The first was to be answered by managers, while the second was to be answered by up to three employees who were subordinates of these managers. The manager questionnaire included reflective scales on manager technical competence (H4-H5) and experience (H6). By contrast, the employee questionnaire included reflective scales on IWO (H1-H6) and manager technical competence (H4-H5) as well as formative scales on employees' use of internal knowledge sources (H1, H6) and the breadth (H2, H4) and depth (H3, H5) of their use of external knowledge sources. The Appendix summarizes the questionnaire items, their sources in the literature, and our procedure for calculating variables based on these items.

To measure IWO, we adopted the widely-used scale by de Jong and den Hartog (2010). From their original six-item scale, we dropped two less innovation-related items on customer acquisition and knowledge acquisition and focused on the remaining four that deal with product and process innovation. This choice meets our conceptual treatment of IWO as the foundation of customer value (Slater 1997), which is 
defined as the ratio of customer benefits over customer sacrifices (e.g., price paid) (Frank et al. 2014a; Woodruff 1997). While product innovation translates into customer value through higher quality and improved functionality (Frank et al. 2014b; Slater 1997; Woodruff 1997), process innovation translates into customer value through operational efficiency and thus lower prices (Wimalachandra et al. 2014a; Woodruff 1997), through higher manufacturing quality (Wimalachandra et al. 2014b), and through higher flexibility and thus responsiveness to customers (Blocker et al. 2011; Slater 1997; Wimalachandra et al. 2014a).

Based on Laursen and Salter (2006), we chose formative constructs to measure the average extent to which employees use entirely distinct types of knowledge sources (i.e., a multidimensional concept), whereas reflective constructs would focus on unidimensional concepts. Thus, we defined the variable of employee use of internal knowledge sources as the average degree of using internal knowledge sources, independent of any specific usage patterns. We defined the variables of breadth and depth of employee use of external knowledge sources as the number of external knowledge sources (i.e., the number of items from items 6 to 13) with a response score $\geq 3$ for breadth and $\geq 6$ for depth on a 7-point scale from not used (1) to routinely used (7). As manager technical competence may be more difficult to measure reliably than our other scales, we defined it as a second-order formative construct calculated as the average score of the manager's selfassessment and the subordinates' average assessment of the manager (Van Minh et al. 2017).

\section{Data collection and sample}

The leadership literature (Badawy 1995) suggests that technical skills are important for top managers in high-tech companies because these skills enable them to effectively communicate with technical employees and to make the right decisions on technical issues. Consequently, we tested our hypotheses in the telecommunications sector, where technological change is rap$\mathrm{id}$, competition is fierce, and managers and employees tend to have technical expertise (Phelps 2010). In this context, employee knowledge acquisition and innovation play significant roles in the success of the firm. Moreover, since our variables (knowledge, IWO, and technical competence) may vary across industries, we selected a single industry to ensure sufficient homogeneity of the sample (Eisenhardt and Schoonhoven 1996), minimize the confounding influence of intervening variables (Van Minh et al. 2017) and, thus, enhance the internal validity of our study (Mohr and Spekman 1994).

We collected data in Vietnam, where innovative employee behavior plays a crucial role in keeping up with the dynamic environment of a rapidly developing emerging market. Based on a governmental list of major telecommunications organizations, we contacted 68 company directors with requests to complete manager questionnaires and distribute employee questionnaires among up to three immediate, technical subordinates with whom they frequently work together. Afterwards, we contacted the directors personally to explain our research and the data collection. We provided all anonymous questionnaires with sealed return envelopes marked to keep track of manager-subordinate teams and supported the data collection on-site. Due to the need for knowledge in a developing country, company directors responded positively to our incentive of sharing the executive summaries of our results and conclusions, which led to a high response rate. Our questionnaires were returned by 52 managers and by 127 subordinate employees, which corresponds to response rates of $76.5 \%$ and $62.2 \%$, respectively. This corresponds to a sample representing teams in approximately $43 \%$ of all established medium or large-sized telecommunications organizations in Vietnam at the time of data collection. After removing questionnaires with missing data, our sample consists of 50 managers and 123 employees, involving up to three subordinates per manager. Despite a rigorous analysis of respondent and (observable) non-respondent characteristics, we did not identify any salient characteristics in the group of non-respondents, not even when we compared early and late respondents (Armstrong and Overton 1977).

For the dataset pooled at the subordinate level across all manager-subordinate teams, Table 1 summarizes the construct correlations and descriptive statistics. In the case of standardized factors, the descriptive statistics refer to the mean across scale items. Most employees extensively use internal knowledge sources and use external knowledge sources broadly, but not deeply. As reported in the Appendix, our reflective constructs fulfill the following requirements of convergent and discriminant validity: Cronbach's $\alpha \geq .7$, item loadings significant, average variance extracted $[\mathrm{AVE}] \geq .5$, and AVE > maximum variance shared with other constructs (Hair et al. 2010). Since the second-order construct of manager technical competence is partially derived from a mean of subordinate employees' evaluations of their manager, we verified the validity of our aggregation across groups of subordinates. As reported in the Appendix, the within-group agreement fulfills the requirement of $\mathrm{R}_{\mathrm{wg}} \geq .7$ (Bliese 2000).

Common method variance (CMV) can be the source of misleading results. To minimize CMV, we kept the surveys short; used reflective, formative, and objective measures with different scale anchors (see Appendix); and combined data from different sources (different surveys for managers and subordinates) for the most important hypothesis tests (H4 H6) (Lindell and Whitney 2001). In addition, we assessed the presence of CMV. According to Lindell and Whitney (2001), the second-lowest positive correlation among measurement items is a conservative upper bound on CMV, whereas negative correlations indicate the absence of CMV. As the result of analyzing correlations among individual 


\section{Correlations}

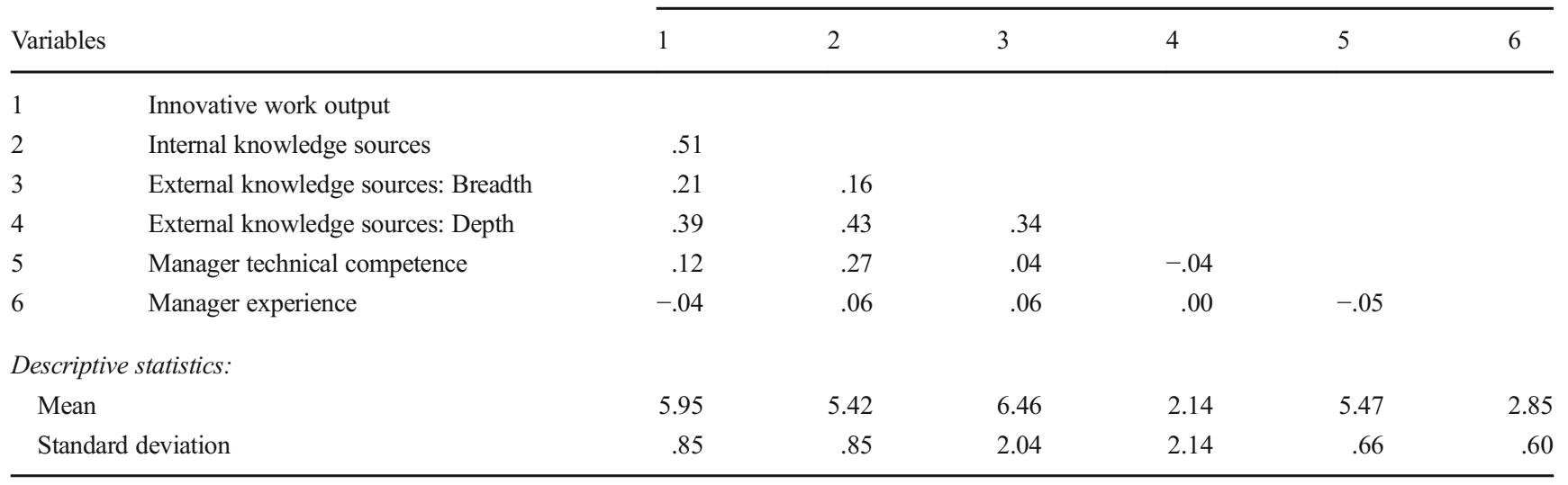

All correlations with $|\mathrm{r}|>.17$ significant at $p<.05$ (two-sided). Sample size: 123

Descriptive statistics for factors: mean score across non-standardized items

construct items of employees' use of knowledge sources and employees' evaluations of manager technical competence, negative correlations are present and the second-lowest positive, non-significant correlation amounts to merely .020 . Hence, CMV is not likely to be an issue in our study.

\section{Results}

\section{Hypothesis tests}

Accounting for the nested structure of manager-subordinate teams with subordinate employees (i) at level 1 and their managers (j) at level 2, we tested our hypotheses using hierarchical linear modeling (HLM) (Kreft and de Leeuw 1998). Our HLM models include employee IWO (H1-H6) as the dependent variable as well as employee use of internal knowledge sources (H1, H6) (Int_KS), breadth (H2, H4) and depth (H3, H5) of employee use of external knowledge sources (Ext_KS_Breadth/Depth), manager technical competence (MgrTC), and manager experience (MgrE) as independent variables. Control variables include the duration of the manager-employee relationship (MgrEmp_RelD) and manager age (MgrAge) to reduce the likelihood of misinterpreting the effects of manager experience (H6) and manager technical competence (H4-H5). In addition, our HLM models include an intercept $\left(\gamma_{00}\right)$ and error terms at levels $1\left(\varepsilon_{\mathrm{ij}}\right)$ and $2\left(\mathrm{u}_{0 j}\right)$. In line with past findings of non-linear, squared effects of a firm's use of knowledge sources (Laursen and Salter 2006), our HLM models also include squared terms of all types of employee use of knowledge sources (H2). To test the moderating effects of manager characteristics, our HLM models further include interaction terms calculated by multiplying manager technical competence (H4-H5) and manager experience (H6) with all types of employee use of knowledge sources. We standardized our dependent and independent variables before calculating squared terms and interaction terms. Below, we specify the model structure in equation form.

Level 1:

$$
\begin{aligned}
\text { IWO }_{\mathrm{ij}}= & \beta_{0 \mathrm{j}}+\beta_{1 \mathrm{j}}\left({\mathrm{MgrEmp} \_R e l D_{\mathrm{ij}}}\right)+\beta_{2 \mathrm{j}}\left(\text { Int_KS }_{\mathrm{ij}}\right) \\
& +\beta_{3 \mathrm{j}}\left(\text { Int_KS }_{\mathrm{ij}}\right)^{2}+\beta_{4 \mathrm{j}}\left(\text { Ext_KS_Breadth }_{\mathrm{ij}}\right) \\
& +\beta_{5 \mathrm{j}}\left(\text { Ext_KS_Breadth }_{\mathrm{ij}}\right)^{2}+\beta_{6 \mathrm{j}}\left(\text { Ext_KS_Depth }_{\mathrm{ij}}\right) \\
& +\beta_{7 \mathrm{j}}\left(\text { Ext_KS_Depth }_{\mathrm{ij}}\right)^{2}+\varepsilon_{\mathrm{ij}}
\end{aligned}
$$

Level 2:

$$
\begin{aligned}
\beta_{0 \mathrm{j}}= & \gamma_{00}+\gamma_{01}\left(\operatorname{MgrAge}_{\mathrm{j}}\right)+\gamma_{02}\left(\operatorname{MgrTC}_{\mathrm{j}}\right) \\
& +\gamma_{03}\left(\operatorname{MgrE}_{\mathrm{j}}\right)+\mathrm{u}_{0 \mathrm{j}} \\
\beta_{1 \mathrm{j}}= & \gamma_{10} \\
\beta_{2 \mathrm{j}}= & \gamma_{20}+\gamma_{21}\left(\operatorname{MgrTC}_{\mathrm{j}}\right)+\gamma_{22}\left(\operatorname{MgrE}_{\mathrm{j}}\right) \\
\beta_{3 \mathrm{j}}= & \gamma_{30}+\gamma_{31}\left(\operatorname{MgrTC}_{\mathrm{j}}\right)+\gamma_{32}\left(\operatorname{MgrE}_{\mathrm{j}}\right) \\
\beta_{4 \mathrm{j}}= & \gamma_{40}+\gamma_{41}\left(\operatorname{MgrTC}_{\mathrm{j}}\right)+\gamma_{42}\left(\operatorname{MgrE}_{\mathrm{j}}\right) \\
\beta_{5 \mathrm{j}}= & \gamma_{50}+\gamma_{51}\left(\operatorname{MgrTC}_{\mathrm{j}}\right)+\gamma_{52}\left(\operatorname{MgrE}_{\mathrm{j}}\right) \\
\beta_{6 \mathrm{j}}= & \gamma_{60}+\gamma_{61}\left(\operatorname{MgrTC}_{\mathrm{j}}\right)+\gamma_{62}\left(\operatorname{MgrE}_{\mathrm{j}}\right) \\
\beta_{7 \mathrm{j}}= & \gamma_{70}+\gamma_{71}\left(\operatorname{MgrTC}_{\mathrm{j}}\right)+\gamma_{72}\left(\operatorname{MgrE}_{\mathrm{j}}\right)
\end{aligned}
$$

Table 2 shows that the independent variables explain 52\% of the variance in employee-level IWO. This value is five times as high as in Laursen and Salter's (2006) study on 
firm-level innovation and, thus, may indicate relatively high relevance of knowledge sources and manager characteristics to employee-level, compared to firm-level, innovation processes. Since our fully-specified HLM model does not contain any even marginally significant squared effect of depth of employee use of external knowledge sources, either as a main or moderating effect, we based our conclusions on a reduced model (right column of Table 2), which excludes these squared, nonsignificant effects. Figure 2 visualizes our results.

Our hypothesis tests indicate that employee use of internal knowledge sources and depth of employee use of external knowledge sources exert positive linear effects on IWO (H1 and $\mathrm{H} 3$ supported). The effect of breadth of employee use of external knowledge sources on IWO has an inverse U-shape (H2 supported). Higher technical competence of the manager in charge shifts this curve to the left and exposes employees to the down-curving part of the inverse U-shape to a greater extent. In other words, the higher the technical competence of the manager in charge, the more negative, or less positive, the effect of breadth of employee use of external knowledge on IWO (H4 supported). Also, manager technical competence enhances the effect of depth of employee use of external knowledge sources on IWO (H5 supported). Moreover, manager experience enhances the effect of employee use of internal knowledge sources on IWO (H6 supported). Beyond the scope of our hypotheses, the positive effect of employee use of internal

Table 2 Effects of employee use of internal and external knowledge sources on IWO

\begin{tabular}{|c|c|c|c|}
\hline Independent variable & $\begin{array}{l}\text { Full model } \\
\beta\end{array}$ & $\begin{array}{l}\text { Reduced model } \\
\beta\end{array}$ & Hypotheses \\
\hline \multicolumn{4}{|l|}{ Control variables (levels 1 and 2): } \\
\hline Intercept & $.327 * *$ & $.286^{*}$ & \\
\hline Manager age & .086 & .085 & \\
\hline Manager-employee relationship duration & .061 & .063 & \\
\hline \multicolumn{4}{|c|}{ Employee use of internal and external knowledge sources (level 1): } \\
\hline Internal knowledge sources & $.355^{* * *}$ & $.362 * * *$ & $\mathrm{H} 1:+$ \\
\hline (Internal knowledge sources) $^{2}$ & -.071 & -.073 & \\
\hline External knowledge sources: Breadth & -.158 & -.165 & \\
\hline$(\text { External knowledge sources: Breadth })^{2}$ & $-.170^{*}$ & $-.183 *$ & H2: - \\
\hline External knowledge sources: Depth & $.263 *$ & $.202 * *$ & $\mathrm{H} 3:+$ \\
\hline${\text { (External knowledge sources: Depth })^{2}}^{2}$ & -.058 & & \\
\hline \multicolumn{4}{|l|}{ Moderating effects of manager characteristics (level 2): } \\
\hline Manager technical competence (MgrTC) & .060 & .063 & \\
\hline MgrTC $\times$ Internal knowledge sources & -.046 & -.045 & \\
\hline MgrTC $\times(\text { Internal knowledge sources })^{2}$ & -.054 & -.046 & \\
\hline MgrTC $\times$ External knowledge sources: Breadth & $-.312 *$ & $-.314 *$ & H4: - \\
\hline MgrTC $\times(\text { External knowledge sources: Breadth })^{2}$ & -.054 & -.052 & \\
\hline MgrTC $\times$ External knowledge sources: Depth & .124 & $.153 *$ & H5: + \\
\hline MgrTC $\times(\text { External knowledge sources: Depth })^{2}$ & .011 & & \\
\hline Manager experience (MgrE) & -.015 & -.027 & \\
\hline MgrE $\times$ Internal knowledge sources & $.183^{*}$ & $.202 *$ & H6: + \\
\hline MgrE $\times(\text { Internal knowledge sources })^{2}$ & $-.152 * *$ & $-.154 * *$ & \\
\hline MgrE × External knowledge sources: Breadth & -.037 & -.040 & \\
\hline MgrE $\times(\text { External knowledge sources: Breadth })^{2}$ & .051 & .044 & \\
\hline MgrE $\times$ External knowledge sources: Depth & .098 & .083 & \\
\hline MgrE $\times(\text { External knowledge sources: Depth })^{2}$ & -.025 & & \\
\hline \multicolumn{4}{|l|}{ Fit statistics: } \\
\hline HLM Pseudo $\mathrm{R}^{2}$ (Kreft and de Leeuw 1998) & .524 & .521 & \\
\hline Sample size & 123 & 123 & \\
\hline
\end{tabular}

${ }^{\dagger} p<.1 ;{ }^{*} p<.05 ;{ }^{* *} p<.01 ;{ }^{* * * *} p<.001$ (two-sided). All variables standardized before calculating interaction terms.

Hierarchical linear modeling (HLM) with maximum likelihood estimation 

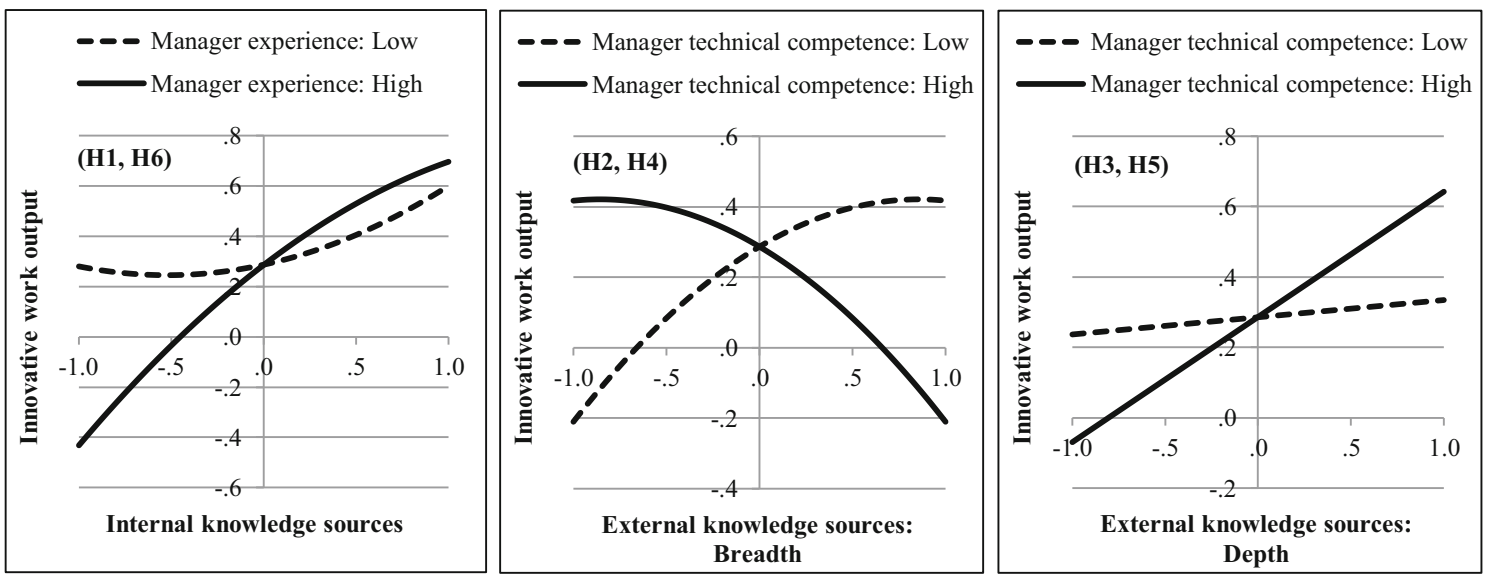

Fig. 2 Visualized effects of employee use of internal and external knowledge sources on IWO. Notes: Axis unit: standard deviations from mean. Moderator unit for high/low: \pm 1 standard deviation from mean

knowledge sources on IWO takes a slightly up-curving shape for low manager experience and a slightly down-curving shape for high manager experience. This may indicate that extensive use of internal knowledge sources (e.g., colleagues) helps employees compensate for a lack of manager experience and that manager experience has greater leverage when employees do not use internal knowledge sources extensively.

\section{Additional analyses and robustness tests}

Aggregated team knowledge Further post-hoc analyses verified whether the aggregated use of individual knowledge sources (i.e., selection of the highest score for each knowledge source) across the subordinates of a manager, which is a proxy measure of the maximum knowledge brought into a manager's team from all consulted sources, has any additional main or moderating effects on IWO. However, these effects were not significant $(p>.1)$.

Ordinary least squares and robust errors As a robustness test, we recalculated our models using ordinary least squares, both with regular and heteroskedasticity-robust standard errors. The results resemble those obtained for HLM and lead to the same conclusions with respect to all hypothesis tests.

Without measures of breadth and depth For another robustness test, we operationalized the employee's use of external knowledge sources not by measures of breadth (H2, H4) and depth (H3, H5), but by the average use of external knowledge sources (mean score of items 6 to 13, analogous to the operationalization of the employee's use of internal knowledge sources). The results resemble those obtained for depth of employee use of external knowledge sources (H3, H5). Thus, they confirm both the contribution of external knowledge to an employee's IWO and the role of the manager's technical competence in facilitating the employee's use of external knowledge sources. As with our main analysis,
IWO appears to be derived to a greater extent from internal rather than external knowledge sources (almost double the effect size).

Breadth and depth of use of internal knowledge sources For yet another robustness test, we operationalized the employee's use of internal knowledge sources by measures of breadth and depth, as with the external knowledge sources. These formative measures vary from 0 to 5 , depending on the number of internal knowledge sources used occasionally (breadth: counted if score $\geq 3$ ) or extensively (depth: counted if score $\geq 6$ ). As with the previous robustness test, the results obtained for depth of use of internal knowledge sources resemble those obtained in our main analysis for the average use of internal knowledge sources, both regarding its effect on IWO (H1) and the role of manager experience in moderating its effect (H6). In contrast, the measure of breadth of use of internal knowledge sources does not capture sufficient variation to allow any valid conclusions to be drawn (mean $=4.87$ on a scale from 0 to 5) because virtually every employee uses all internal knowledge sources at least occasionally.

Interactions between the employee's use of internal and external knowledge sources In response to a discussion in the open innovation literature (Cassiman and Veugelers 2006; Cohen and Levinthal 1990; West and Bogers 2014), we further verified whether internal and external knowledge interact in producing IWO. However, the effects of such interaction terms were not significant for measures of average use of knowledge sources or for measures of breadth and depth of the use of these sources.

\section{Comparison of the effects of individual knowledge sources In} line with previous research on open innovation (Laursen and Salter 2006; Salter et al. 2014), the conceptual focus of our study is on the effects of more overall knowledge and of knowledge from more sources on IWO. As an additional 
analysis, we chose to compare across different knowledge sources the degree to which more extensive use of the same individual knowledge source influences IWO. To produce valid multi-item measures, we conceptually identified different sets of knowledge sources with similar purposes, replicated these sets with an exploratory factor analysis, and separately extracted the following factors of an employee's use of knowledge sources (see Appendix): employee use of colleague-related internal sources (items 1 to $3 ; \mathrm{AVE}=.57$; $\alpha=.78$ ), self-related internal sources (items 4 to 5 ; $\mathrm{AVE}=.61 ; \alpha=.76$ ), market-related external sources (items 7 and $9 ; \mathrm{AVE}=.75 ; \alpha=.86$ ), non-market-related external sources (items 6 and $8 ; \mathrm{AVE}=.52 ; \alpha=.68$ ), and researchrelated external sources (items 10 to $13 ; \mathrm{AVE}=.71 ; \alpha=.90$ ). These factors marginally fulfill the following requirements of convergent and discriminant validity: Cronbach's $\alpha \geq .7$ (sometimes described as $\alpha \geq .6$ ), item loadings significant, $\mathrm{AVE} \geq .5$, and $\mathrm{AVE}>$ maximum variance shared with other constructs (Hair et al. 2010). Our results indicate that the employee's use of both self-related and colleague-related internal knowledge sources, the use of non-market-related external knowledge sources (largest effect), and the use of R\&D contractors (but not other research-related external sources) contribute to IWO. Hence, while our previous results show that IWO is derived to a greater extent from employee use of internal rather than external knowledge sources, these results indicate that certain external knowledge sources are more influential than internal knowledge sources.

\section{Comparison of effects on product innovation versus process} innovation In our IWO scale (see Appendix, de Jong and den Hartog 2010), items 1 and 3 are more closely related to product innovation, whereas items 2 and 4 are more closely related to process innovation, although it is difficult to make a clear distinction between multiple items intended to measure a unidimensional construct. Within the limitations of such a separation, we extracted separate factors for product innovation $(\mathrm{AVE}=.60, \alpha=.75)$ and process innovation $(\mathrm{AVE}=.66$, $\alpha=.80$ ), whose Pearson correlation amounts to $r=.74$. These sub-dimensional factors satisfy the following requirements of convergent and discriminant validity: Cronbach's $\alpha \geq .7$, item loadings significant, $\mathrm{AVE} \geq .5$, and $\mathrm{AVE}>$ maximum variance shared among constructs (Hair et al. 2010). Variants of our hypothesis tests for these alternative dependent variables lead to results that are very similar to our main analysis (see Table 2), with a key difference between the formation of product and process innovation. Breadth of employee use of external knowledge sources has an inverse U-shaped effect on process innovation, but not on product innovation, for which depth appears to be slightly more important. This result appears reasonable as process innovation may consist of minor process improvements, for which shallow knowledge (i.e., a certain degree of breadth) can be beneficial, whereas product innovation tends to require the completion of major tasks and, thus, benefits more from depth of knowledge.

Meta-analytic comparison of emerging and developed markets To help gain an understanding of employee-level open innovation in emerging markets, we conducted a metaanalysis to compare our effect sizes to those of comparable research in developed markets. In this limited literature, only two recent studies examine the influence of an employee's use of external knowledge sources on their IWO. Both studies focus on R\&D department employees in a developed market (Dahlander et al. (2016): IBM in the U.S.; Salter et al. (2015): one anonymous firm in a European developed market), whereas our study focuses on technical employees in general (in both $R \& D$ and non-R\&D departments) in a developing market. Unlike our study, these studies do not control for employee use of internal knowledge sources. As in most meta-analyses, we compared effect sizes across studies using the overall correlation of variables because comparisons of effect sizes in multivariate analyses are biased by study differences in the included sets of independent variables (Grewal et al. 2018; Rosenthal 1991).

Dahlander et al. (2016) examine the effect of the breadth of an employee's external search (but not depth) on IWO (measured by patents) with a sample size of 330 . The overall correlation is $r=.11$, compared with our correlation of $r=.21$. Therefore, while our study shows a nominally stronger correlation between the breadth of an employee's external search and IWO, our meta-analysis (method by Rosenthal 1991) indicates that the difference is not significant $(p=.175)$. Thus, this result does not suggest that the importance of the breadth of external search for IWO differs between emerging and developing markets. However, while our analysis (see Table 2) finds that the breadth of external search has an inverse Ushaped effect on IWO, Dahlander et al. (2016) report a linear effect, which could be explained by a much lower mean value of breadth of external search in their study and, thus, by more employees operating in the lower, yet increasing zone of the inverse U-shaped effect. Potentially, the availability of more knowledge in a developed market firm (Fu et al. 2014) limits the tendency to search excessively for external information.

Using a sample of 329 employees, Salter et al. (2015) explore the effect of an employee's overall external search, without any distinction made between breadth and depth, on IWO. Our meta-analysis indicates that their correlation of $r=.06$ is significantly $(p<.001)$ lower than our $r=.40$ for an analogous measure used in our supplementary analysis without measures of breadth and depth reported above. Therefore, bearing in mind the limitations of a two-study comparison, we conclude that employee use of external knowledge sources appears to be more important for IWO in an emerging market than in a developed market. 
No other study appears to explore whether manager characteristics moderate the effects of employee use of internal and external knowledge sources on IWO. Of partial relevance to our study, Ahn et al. (2017) use data from South Korea (2017 GDP/Capita: US\$ 29,938; Vietnam: US\$ 2307; Countryeconomy 2019) to examine the role of CEO characteristics (rather than the direct supervisor's characteristics) in initiating (rather than facilitating) an employee's external search in innovation processes. They find that neither manager experience nor manager education (similar to manager technical competence) helps initiate an employee's external knowledge sourcing, which matches our correlation results (see Table 1).

\section{Research extension: the effects of employee use of knowledge sources on customer acquisition}

Originally, we dropped items on employee customer acquisition and employee knowledge acquisition from de Jong and den Hartog's IWO scale (2010) because these employee behaviors do not match our conceptualization of employee-level innovation, which serves as the foundation of customer value (Slater 1997; Woodruff 1997), in the narrow sense. However, as an extension of value to marketing scholars and practitioners, we performed additional analyses on whether an employee's use of knowledge sources affects customer acquisition, which has received little attention in the marketing literature. According to Bergkvist and Rossiter's measurement rule (2007), the construct of employee customer acquisition fulfills the conditions for measurement with a single item (see Appendix) because the construct deals with a concrete attribute (customer acquisition for the firm) and a concrete object (new groups of customers). Based on the same statistical models that we used for our other analyses, we obtained the following results when using employee customer acquisition as the dependent variable.

Employee use of external knowledge sources influences customer acquisition positively, whereas employee use of internal knowledge sources has an inverse U-shaped relationship with customer acquisition and, thus, only pays off to a certain extent. After all, employees acquire customers outside the firm, whereas they mostly produce innovation outcomes (effect size: internal sources > external sources) inside the firm. Regarding external knowledge sources, only breadth affects customer acquisition, whereas depth does not have any significant effect. As customer acquisition is reliant on less complicated knowledge than innovation processes, it does not require the same depth when engaging individual knowledge sources. Neither manager technical competence nor manager experience appears to moderate the effects of employee use of internal and external knowledge sources. This finding indicates that employees leverage less complicated knowledge during customer acquisition than during innovation processes, so they require less managerial facilitation.

While these analyses focus on the effects of more overall knowledge and of knowledge from more sources on customer acquisition, we also performed an additional analysis to compare whether obtaining more knowledge from an individual source affects customer acquisition across knowledge sources. The results show that the employee's use of market-related external knowledge sources (largest effect), research-related external knowledge sources, and self-related internal knowledge sources influence customer acquisition positively. As expected, customer-related knowledge sources (part of market-related external knowledge sources) play the most important role. These relationships are in contrast to the formation of IWO, for which the employee's use of non-marketrelated external knowledge sources and colleague-related internal knowledge sources are highly influential.

\section{Discussion and conclusions}

\section{Summary of research objectives and hypothesis tests}

Our study examines whether firms in an emergent market can strategically deploy the appropriate managerial resources to help their employees leverage internal and external knowledge sources into innovative output. Our theoretical approach highlights the microfoundations and dynamics of open innovation and, thus, presents a complementary viewpoint to the macro-organizational approach that is more prevalent in the open innovation literature. We build on open innovation research at the firm level, which highlights the importance of internal and external knowledge sources for a firm's innovativeness, and we consider the individual employee as the basic unit of analysis for open innovation. Within our unique perspective, we examine whether internal and external sources of knowledge used by employees in their search for innovative opportunities influence their IWO (H1-H3). Moreover, we investigate whether managerial characteristics, such as manager experience and technical competence, moderate the effectiveness of employee use of internal and external knowledge sources on IWO (H4-H6). Therefore, we link internal, external, and managerial resources in explaining separate and synergistic effects on employee-level open innovation.

To test our hypotheses, we analyzed nested, multi-source data, which we collected from managers and their subordinate employees at telecommunications companies in the emerging market of Vietnam. We find strong evidence that employee use of both internal and external knowledge sources influences IWO (H1-H3) and that their managers' level of experience and technical competence each plays an important role in moderating these relationships (H4-H6). Specifically, our findings show that individual employees' use of internal 
knowledge sources (H1) and the depth of their use of external knowledge sources (H3) both have a positive influence on IWO. In contrast, the breadth of employee use of external knowledge sources has an inverted U-shaped effect on IWO (H3). Our results also highlight the important roles that managers play in helping employees to benefit from their knowledge search. We find that a manager's experience helps subordinate employees leverage internal knowledge sources into IWO (H6), whereas manager technical competence helps employees leverage depth (H5), and cope with low breadth (H4), of external knowledge source use.

\section{Theoretical implications}

As presented in Table 3, our research has a number of theoretical implications that go beyond making a contribution to the literature on open innovation in emerging markets (Bogers et al. 2019; Kafouros and Forsans 2012), and connects with recent research on conditions for innovation in firms in emerging markets (Singh and Gaur 2018; Xie and Li 2018). Building on the literature on the role of individuals in open innovation, which mostly focuses on developed markets (e.g., Ahn et al. 2017; Dahlander et al. 2016; Salter et al. 2015), our study adds to the understanding of the causal mechanisms and contingencies of these processes specifically for firms in emerging markets. This not only adds new insights into the relative roles of the breadth and depth of external searches and, more generally, into the importance of external search in emergent markets to compensate for a lack of knowledge, but also opens up a new emergent market perspective for developing theory on open innovation.

First, our study addresses the call in the open innovation literature for more research based on the individual level of analysis. Organization-level open innovation is not merely an aggregation of employee-level open innovation activities. Rather, it results from team-level processes, organizational facilitation, and very heterogeneous employee contributions (Coff and Kryscynski 2011; Felin et al. 2015) including employees whose efforts are hindered by organizational constraints and other employees that block organizational open innovation initiatives (Salter et al. 2014). In addition, organization-level open innovation takes on different forms such as in-sourcing, in-licensing, out-licensing, corporate venturing, innovation intermediaries, innovation tournaments, and open-source software development (Ahn et al. 2017; Salter et al. 2014), for which individual employees play different roles. While the extant literature addresses the output of open innovation at the firm level of analysis (Laursen and Salter 2006) and, to some extent, at the development project level (Salge et al. 2013), little is known about the employee level of analysis: the employees "operating on the front lines of open innovation" (Salter et al. 2014, p. 78). Consequently, the open innovation literature calls for more research based on the employee level of analysis to disentangle heterogeneous employee activities, team activities, and organizational efforts and understand the potential for organizational facilitation of employee activities. A deeper, micro-level understanding of how organizational choices, such as the selection of managers with certain characteristics, interact with employee behavior may provide an explanation as to why the open innovation performance of firms differs despite having access to the same external sources (Felin et al. 2015). Our study responds to this call for research by investigating both employee-level open innovation activities and the role of managers in facilitating these activities.

The limited recent research on employee-level open innovation reveals that an employee's openness to external sources of knowledge plays an important role in certain aspects of the innovation process, such as ideation (Salter et al. 2015), coping strategies (Salter et al. 2014), leadership (Rangus and Černe 2019), and the evaluation of entrepreneurial opportunities (Autio et al. 2013). By extending this literature, our research leads to a broader theoretical understanding of the "human side" and "microfoundations" of open innovation (Ahn et al. 2017; Bogers et al. 2017, 2018). We find that the effects of the employee's internal and, more importantly, external knowledge search on IWO are curvilinear. Our study is the first to find that internal searches are more effective than external searches and that the depth of an external search is more effective than the breadth of an external search. Also, the breadth of an external search is only effective below a certain threshold, beyond which the additional costs of searching exceed the benefits for IWO. Ultimately, these findings add to the mixed effects found in organization-level innovation research (Katila and Ahuja 2002; Laursen and Salter 2006; Svetina and Prodan 2008; Terjesen and Patel 2017; Wu et al. 2013).

Second, extant research on open innovation focuses almost exclusively on R\&D employees (Salter et al. 2015) and elite boundary spanners (Dahlander et al. 2016) and excludes nonR\&D employees. Therefore, we address this omission by focusing on technical employees in general, including both $R \& D$ and non-R\&D employees. A broader view on the employee base of an organization is particularly important in contemporary high-tech organizations as innovation is no longer solely the task of scientists, R\&D professionals, or "elite boundary spanners" (Dahlander et al. 2016; Salter et al. 2015). These organizations promote, develop, and use the innovative potential of all technical employees to remain competitive (Axtell et al. 2000; Dorenbosch et al. 2005; Van Minh et al. 2017). Such distributed innovation leads to increased customer value and follows the diffusion of market orientation within high-tech firms, as captured by research on the diffusion of product orientation within firms (Lam et al. 2010). Our findings on how employees in both $R \& D$ and non-R\&D settings leverage internal and external knowledge sources into IWO 

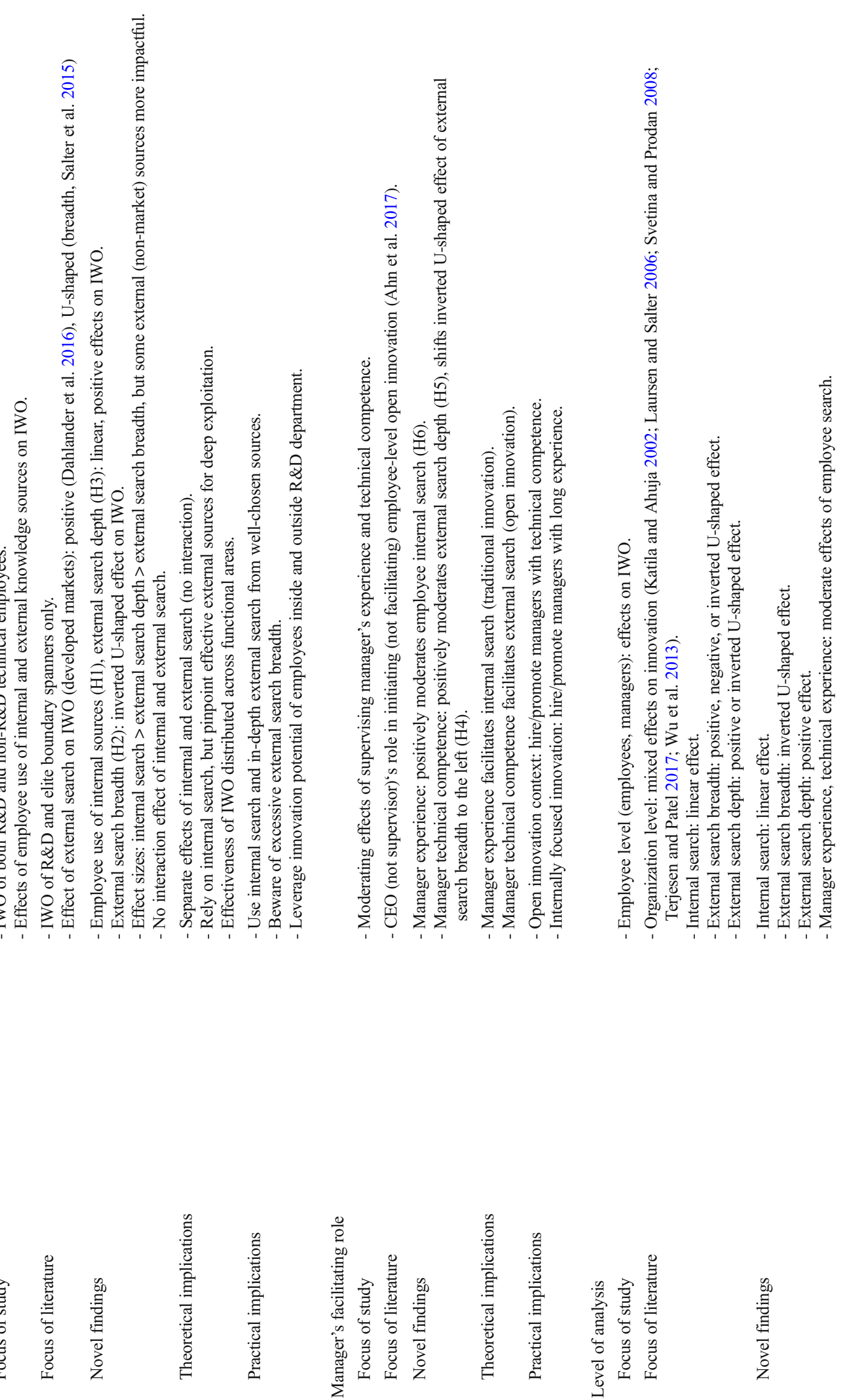

D
:
0
0
0
0
$z$
$z$ 


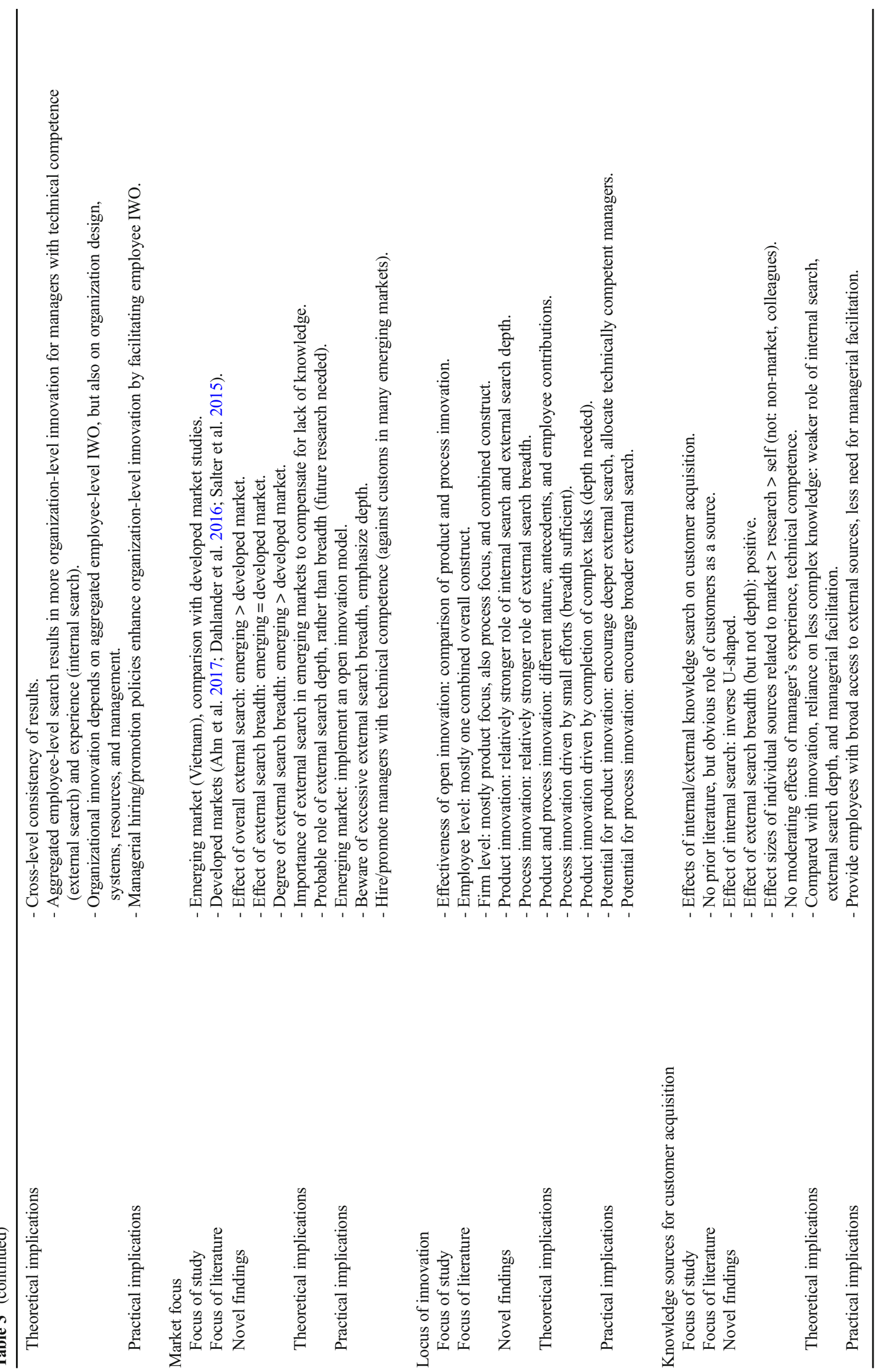


underscore the relevance of distributed information and link to other literature to create a more complete picture of employee involvement in open innovation. Possible perspectives here are a focus on such employees as a central element of a firm's key resources (Amabile 1988; Becker and Huselid 2006), boundary spanning (Allen 1977), and absorptive capacity (Cohen and Levinthal 1990) in line with the firm's broader open innovation model (Chesbrough and Bogers 2014; West and Bogers 2014).

Third, our study addresses unresolved questions in the open innovation literature (Bogers et al. 2017), which has provided mixed results in terms of whether internal and external sources are complements or substitutes in the context of absorptive capacity and open innovation (Cassiman and Veugelers 2006; Cohen and Levinthal 1990; West and Bogers 2014). At the employee level, our findings indicate that the use of internal and external knowledge sources does not interact in driving IWO, but that their contributions are separate. We also find that internal knowledge sources play a larger role than external knowledge sources in contributing to IWO. However, individual external knowledge sources may surpass all individual internal knowledge sources in their contribution to IWO. Specifically, our study identifies a particularly strong effect of non-market-related external knowledge sources on employee-level IWO. These results are important to managers when defining priorities for employee knowledge search activities to ensure that employees search for activities that have a high likelihood of being translated into innovative outcomes. As another novel topic of theoretical interest, our results highlight differences in how the employee's use of internal and external knowledge sources affects product innovation as opposed to process innovation. Both employee use of internal knowledge sources and the depth of use of external knowledge sources contribute relatively more to product innovation, whereas the breadth of use of external knowledge sources is more relevant to process innovation. Such results can help managers define their subordinate employees' knowledge search activities based on the relative importance of product versus process innovation within the organization.

Fourth, our study contributes to the literature by being the first to demonstrate the moderating effects of managerial characteristics on the performance of employees' open innovation practices. Research shows that knowledge acquisition and innovation are social processes which need organizational support. Specifically, the support of immediate managers plays a critical role in how employees acquire knowledge, learn, and innovate (Van Minh et al. 2017; Zhang and Bartol 2010) because managers are aware of their subordinate employees' work activities and have considerable influence on the context wherein these employees' knowledge acquisition and innovation take place (Shalley and Gilson 2004). Along the same lines, recent research on open innovation suggests that individuals in managerial positions play important roles in firms' open innovation practices (Dahlander et al. 2016). However, how an employee's sources of knowledge acquisition interact with the organization's internal managerial characteristics that are required for successful innovation is not yet understood (West and Bogers 2014). Our study fills this gap in the literature by illuminating the critical roles that a manager's experience and technical competence play in facilitating the effects of a subordinate employee's use of internal and external knowledge sources on IWO. We show that the manager's experience and technical competence play differential roles. While manager experience facilitates the employee's use of internal knowledge sources, manager technical competence facilitates the employee's use of external knowledge sources and differentially affects the outcomes of the breadth and depth of the external search. Such insights can help organizations decide which type of leader is most appropriate for enhancing the effectiveness of employees' search activities. As a secondary result, we find that the manager's experience and technical competence do not help initiate subordinate employees' openness in sourcing external knowledge, which concurs with Ahn et al. (2017).

Fifth, this study extends our understanding of open innovation in emerging markets. This is critical because theories based on assumptions and findings for firms in developed markets may not apply to firms in emerging markets (Luo et al. 2011). Based on the meta-analysis, our study compares the effects of employee-level open innovation in an emerging market to the very small number of analogous studies on developed markets. This comparison indicates that employee use of external knowledge sources is more effective in emerging markets than in developed markets, perhaps because firms in emerging markets have less or poorer internal knowledge (Fu et al. 2014) that employees can leverage into IWO. This corresponds with research that emphasizes that firms in emerging markets invest in absorptive capacity to facilitate learning from others (Luo et al. 2011) and to substitute for weaker internal knowledge creation. At the same time, employees in our emerging market setting exhibit much higher external search breadth, with many employees exceeding the optimal threshold for external searches, resulting in decreased IWO, which is not the case in the developed market setting. In combination, these conclusions imply that the depth of the external search, rather than the breadth, may be particularly important for firms in emerging markets, where learning from others is crucial for overcoming a lack of knowledge, which otherwise limits the capacity to innovate.

Sixth, as an extension of our main analysis, our study is the first to address whether employee use of internal and external knowledge sources contributes to customer acquisition. 
Analogous to the open innovation concept, we find that external sources play an even greater role than internal sources in customer acquisition processes. However, unlike with openness in innovation processes, only the breadth - but not depth — of the employee's use of external knowledge sources contributes to customer acquisition, which is probably due to the less knowledge-intensive nature of customer acquisition processes compared with innovation processes. Among multiple sets of knowledge sources, market-related external knowledge sources contribute to customer acquisition outcomes most strongly, followed by research-related external knowledge sources, and self-related internal knowledge sources.

\section{Managerial implications}

First and foremost, the results of our study are important for managers in emerging market firms, as they highlight that open innovation is more effective in an emerging market than in developed markets, which are the dominant focus of past research. Hence, we advise managers in emerging markets to consider adopting the open innovation concept, which may be beneficial as many firms in emerging markets still lack knowledge (Fu et al. 2014). At the same time, our results identify some of the key limitations and moderating effects that should be considered when implementing an open innovation strategy. In particular, employees in firms in emerging markets appear to search very broadly, but not deeply, across external knowledge sources, which risks reducing their innovative output. Thus, we recommend that managers in firms in emerging markets instruct employees to engage in deep, rather than excessively broad, external searches for information. Furthermore, firms may also take strategic actions such as designing the structure of internal processes and forming strategic alliances with a limited number of carefully selected, knowledgeable partners to direct employees toward external search depth.

Of general interest to managers of high-tech firms, our article emphasizes the fact that innovative behavior, which is a potential source of customer value (Frank et al. 2014a, b), not only occurs among R\&D employees, but also among all technical employees. This insight extends past marketing research on the diffusion of market orientation (Deshpandé and Farley 2004) and product orientation (Lam et al. 2010) within the firm. Drawing on a greater pool of innovators distributed across functional areas increases the firm's potential for organizational innovativeness and, thus, consequential improvements in customer value (Frank et al. 2014b) and competitive advantage in an increasingly competitive market.

In addition, our results are valuable to firms that are seeking to improve their hiring and promotion practices as they highlight the manager's role in directing employees to different knowledge sources and helping them translate this knowledge into innovation outcomes. We show that the effectiveness of this managerial role critically depends on the manager's characteristics. In particular, firms that still adopt a closed, rather than open, innovation system, but also all other firms where internal knowledge sources play an important role, may need to rely on managers with a long experience (H6) to help subordinate employees translate knowledge gained from internal sources into innovation. Experienced managers know where to find internal knowledge, how to access it, while they are also familiar with it, all of which helps employees benefit from internal knowledge. However, organizations that adopt an open innovation strategy may need to rely on managers with high technical competence to help subordinate employees translate knowledge gained from external sources into innovation (H4-H5). Therefore, we advise high-tech organizations that are adopting an open innovation strategy to include not only experience, but also technical competence, in the criteria for choosing managers. Sole reliance on experience, which is the case in many organizations, may hamper the implementation of open innovation and, consequently, organizations may not reap the potential benefits of open innovation. More generally, when considering the aggregation of employee-level actions to organization-level outcomes (following a microfoundations perspective; Felin et al. 2015), managers appear to play an important role in shaping the mechanisms that enable such processes. In other words, placing the right managers in supervisory positions will lead the same employee actions to aggregate into much stronger organization-level innovative output. This is especially important for firms in emerging markets, where the average firm still lacks sophisticated knowledge and critically depends on knowledge from external sources (Deshpandé and Farley 2004; Fu et al. 2014). In addition, firms in many countries and, particularly, in many emerging markets are embedded in collectivist cultures, where hiring and promotion practices are frequently based on close personal ties rather than on technical competence (Hofstede 1991). Our research highlights the importance of merit-based hiring and promotion practices based on technical expertise for the manager's ability to effectively bring external knowledge into the firm and leverage it into innovation outcomes.

\section{Limitations and directions for future research}

Our study has a few limitations. While it focuses on the telecommunications industry only, past research shows that high-tech industries share similar characteristics (e.g., fast-changing technology; high competition; complexity; and uncertainty about markets, competition, and technology development) (Mendonça 2009) and that findings on organizational innovativeness thus do not vary significantly across high-tech industries (Deshpandé and Farley 2004). Hence, in line with other scholars (Phelps 2010; Van Minh et al. 2017), we are confident that our results can be generalized across high-tech industries, but 
we encourage future research to replicate our analysis in other industries and to identify potential differences. We imagine that IWO is less important in non-technical work domains, especially in industries where technology plays a weaker role. Future research also might investigate the role of other manager characteristics and might examine the interplay between manager characteristics and employee characteristics. Another intriguing line of inquiry might focus on the role of intrafirm relationship characteristics, regarding the relationships among colleagues or between subordinates and managers, in facilitating or hindering employee-level open innovation practices. Moreover, our supplementary analysis on the contribution of individual knowledge sources to IWO notably does not find any effect of market-related knowledge sources (customer, competitor) on IWO. First, this result contrasts with the marketing literature's understanding of the importance of customer involvement in innovation processes. Thus, it calls into question whether customers really provide innovative ideas or whether they only serve as a precursor for the market success and thus the final selection of ideas, which future research might inspect. Second, this result is interesting for an emerging market, where firms are blamed for stealing ideas from competitors. Possibly, such intellectual property violations derive from organizational efforts, rather than from individual employee activities, which future research may explore in more detail.

In addition, while we focus on emerging markets, we only examine Vietnam, which provides opportunities for future research to investigate employee-level open innovation phenomena in other emerging markets. Our cross-country meta-analysis on the determinants of employee IWO suggests that, in general, an external search is more effective in emerging markets than in developed markets, whereas the effectiveness of external search breadth does not appear to differ. This points to a more prominent role for the depth of an external search in emerging markets, although we are unable to test this hypothesis without conducting an analogous study on developed economies in the literature. Consequently, we call for future research on developed countries and on cross-national comparisons to test and extend our understanding of the differences between emerging and developed markets. Moreover, since our study is the first to focus on managerial facilitation of employeelevel open innovation, we encourage scholars to analyze the role of managerial characteristics in facilitating employees' open innovation practices in developed economies, where the higher complexity of work contexts might boost the role of manager technical competence.

Moreover, employee-level IWO takes place not only in the $R \& D$ department but is distributed across various business functions of the firm, where employees' relative contributions to product and process innovations and their ways of achieving these goals may differ as a result of distinct functional tasks. While we examined employeelevel open innovation practices on average, future research may elucidate their variation across functional areas in terms of differential use of knowledge sources and in terms of differential ways for managers to facilitate their subordinates' IWO. Likewise, while we investigated interaction effects of internal and external knowledge sources on IWO, future research could seek to identify differences in these interaction effects across functional areas such as R\&D, manufacturing, and marketing (Bogers and Lhuillery 2011; Ettlie and Elsenbach 2007).

A methodological limitation of our study is the inclusion of only two control variables. Future research should consider collecting more data to increase methodological rigor. In addition, our study treats the employee's IWO as a process that encompasses both the generation and implementation of ideas. However, the employee's use of knowledge sources might affect idea generation and idea implementation differently, although this was not possible to investigate based on the integrated, unidimensional IWO scale (de Jong and den Hartog 2010). As past research (Salter et al. 2015) examines the impact of external sources on idea generation, but not on idea implementation, we encourage future research to extend our investigation by examining the performance impact of employee openness on idea implementation.

Finally, future research could extend our supplementary analysis of the effects of internal and external knowledge searches on customer acquisition outcomes. In our results, we found that research-related external knowledge sources have an influence on customer acquisition. While the influence of distributors and external service providers on customer acquisition is known, future research might shed more light on the specific role of research contractors. In addition, a manager's facilitation of knowledge searches in customer acquisition appears to depend on managerial skill sets rather than technical competence or length of experience, which is a non-intuitive result as manager experience is typically considered important in marketing and sales environments. Thus, we advise future research to identify the managerial skill sets that facilitate employees' knowledge searches in marketing tasks such as customer acquisition, market prediction, customer service, and customer relationship management.

Acknowledgments The authors extend their gratitude to all survey respondents, editors, and reviewers. Marcel Bogers acknowledges the support of the Novo Nordisk Foundation (grant number: NNF16OC0021630) 


\section{Appendix}

Construct scales, literature sources, and validity statistics

Questions for employees:

Manager-employee relationship duration (open question: years)

- How long have your manager and you been working together for this firm?

Employee innovative work output (7-point Likert type: not often / very often)

- In your job, how often do you make suggestions to improve current products or services?

- In your job, how often do you produce ideas to improve work practices?

- In your job, how often do you actively contribute to the development of new products or services?

- In your job, how often do you optimize the organization of work?

Employee customer acquisition (7-point Likert type: not often / very often)

- In your job, how often do you acquire new groups of customers?

Employee use of knowledge sources (7-point Likert type: not used / routinely used)

In solving problems/challenges you face in your work, the knowledge you use comes from...

1. Colleagues within your company

2. Managers within your company

3. Subordinates within your company

4. Your previous experience

5. Your reading and/or personal search

6. Your personal relationship with other professionals outside your company

7. Customers

8. Suppliers

9. Competitors

10. Universities

11. Public research organizations

12. Contracted R\&D services providers

13. External consultants

Employee evaluation of manager technical competence (7-point Likert-type: totally disagree/agree)

- When team members face technical problems, my manager sometimes provides technical solutions.

- My manager is knowledgeable of most possible technical problems that team members may face.

- My manager is always learning about new technologies and their applications.

- My manager is technically competent and can independently judge all technical issues.

Questions for employees' managers:

Manager age (open question: years)

- How old are you?

Manager experience (open question: years)

- For how many years have you been working in the field of telecommunications in your firm?

- For how many years have you been working as a top manager in your firm?

Manager evaluation of manager technical competence (7-point Likert-type: very low/high)

- Could you rate your understanding of telecommunications networks?

- Could you rate your understanding of new technologies in telecommunications?

- Could you rate your understanding of new services in telecommunications?

\section{Definitions of reflective and formative constructs:}

Innovative work output (reflective construct; de Jong and den Hartog 2010)

Principal axis factoring of all items of employee innovative work output: AVE $=.63 ; \alpha=.86$

Internal knowledge sources (formative construct; Laursen and Salter 2006)

Mean score of items 1 to 5 of employee use of knowledge sources

External knowledge sources: Breadth (formative construct; Laursen and Salter 2006)

Within items 6 to 13 of employee use of knowledge sources, number of items with score $\geq 3$

External knowledge sources: Depth (formative construct; Laursen and Salter 2006)

Within items 6 to 13 of employee use of knowledge sources, number of items with score $\geq 6$

Manager technical competence (second-order formative construct; Van Minh et al. 2017)

Mean of scores of two first-order constructs:

1. Manager evaluation of manager technical competence (reflective construct)

Principal axis factoring of all items: AVE $=.61 ; \alpha=.83$

2. Mean across managers' subordinates of employee evaluation of manager technical competence

Principal axis factoring of all items (reflective construct): $\mathrm{AVE}=.63 ; \alpha=.87$

Reliability of aggregation across subordinates: $\mathrm{R}_{\mathrm{wg}}=.70$

Manager experience (reflective construct; Van Minh et al. 2017)

Principal axis factoring of all items of manager experience: AVE $=.51 ; \alpha=.71$

$A V E$ average variance extracted 
Open Access This article is distributed under the terms of the Creative Commons Attribution 4.0 International License (http:// creativecommons.org/licenses/by/4.0/), which permits unrestricted use, distribution, and reproduction in any medium, provided you give appropriate credit to the original author(s) and the source, provide a link to the Creative Commons license, and indicate if changes were made.

\section{References}

Ahn, J. M., Minshall, T., \& Mortara, L. (2017). Understanding the human side of openness: the fit between open innovation modes and CEO characteristics. $R \& D$ Management, 47(5), 727-740.

Aime, F., Humphrey, S., DeRue, S. D., \& Paul, J. B. (2014). The riddle of heterarchy: power transitions in cross-functional teams. Academy of Management Journal, 57(2), 327-352.

Allen, T. J. (1966). Performance of information channels in the transfer of technology. Industrial Management Review, 8(1), 87-98.

Allen, T. J. (1977). Managing the flow of technology. Cambridge: MIT Press.

Amabile, T. M. (1988). A model of creativity and innovation in organizations. In B. M. Staw \& L. L. Cummings (Eds.), Research in organizational behavior (Vol. 10, pp. 123-167). Greenwich: JAI Press.

Anderson, C. J., Glassman, M., McAfee, R. B., \& Pinelli, T. (2001). An investigation of factors affecting how engineers and scientists seek information. Journal of Engineering and Technology Management, 18(2), 131-155.

Antons, D., \& Piller, F. T. (2015). Opening the black box of "not invented here": attitudes, decision biases, and behavioral consequences. Academy of Management Perspectives, 29(2), 193-217.

Armstrong, J. S., \& Overton, T. S. (1977). Estimating nonresponse bias in mail surveys. Journal of Marketing Research, 14(3), 396-402.

Astley, W. G., \& Sachdeva, P. S. (1984). Structural sources of intraorganizational power: a theoretical synthesis. Academy of Management Review, 9(1), 104-113.

Autio, E., Dahlander, L., \& Frederiksen, L. (2013). Information exposure, opportunity evaluation and entrepreneurial action: an investigation of an online user community. Academy of Management Journal, 56(5), 1348-1371.

Axtell, C. M., Holman, D. J., Unsworth, K. L., Wall, T. D., Waterson, P. E., \& Harrington, E. (2000). Shopfloor innovation: facilitating the suggestion and implementation of ideas. Journal of Occupational and Organizational Psychology, 73(3), 265-285.

Badawy, M. K. (1995). Developing managerial skills in engineers and scientists: Succeeding as a technical manager (2nd ed.). New York: Wiley.

Badir, Y. F., \& O'Connor, G. C. (2015). The formation of tie strength in a strategic alliance's first new product development project: the influence of project and partners' characteristics. Journal of Product Innovation Management, 32(1), 154-169.

Baer, M. (2012). Putting creativity to work: the implementation of creative ideas in organizations. Academy of Management Journal, 55(5), 1102-1119.

Becker, B. E., \& Huselid, M. A. (2006). Strategic human resources management: where do we go from here? Journal of Management, 32(6), 898-925.

Bergkvist, L., \& Rossiter, J. R. (2007). The predictive validity of multiple-item versus single-item measures of the same constructs. Journal of Marketing Research, 44(2), 175-184.

Bhagat, R. S., Kedia, B. L., Harveston, P. D., \& Triandis, H. C. (2002). Cultural variations in the cross-border transfer of organizational knowledge: an integrative framework. Academy of Management Review, 27(2), 204-221.

Black, D. H., \& Synan, C. D. (1997). The learning organization: the sixth discipline. Management Accounting, 75(10), 70-72.

Bliese, P. D. (2000). Within-group agreement, non-independence, and reliability: Implications for data aggregation and analysis. In K. J. Klein \& S. W. J. Kozlowski (Eds.), Multilevel theory, research, and methods in organizations: Foundations, extensions, and new directions (pp. 349-381). San Francisco: Jossey-Bass.

Blocker, C. P., Flint, D. J., Myers, M. B., \& Slater, S. F. (2011). Proactive customer orientation and its role for creating customer value in global markets. Journal of the Academy of Marketing Science, $39(2), 216-233$.

Bogers, M., Afuah, A., \& Bastian, B. (2010). Users as innovators: a review, critique, and future research directions. Journal of Management, 36(4), 857-875.

Bogers, M., Burcharth, A., \& Chesbrough, H. (2019). Open innovation in Brazil: exploring opportunities and challenges. International Journal of Innovation, 7(2), 178-191.

Bogers, M., Foss, N. J., \& Lyngsie, J. (2018). The "human side" of open innovation: the role of employee diversity in firm-level openness. Research Policy, 47(1), 218-231.

Bogers, M., \& Lhuillery, S. (2011). A functional perspective on learning and innovation: investigating the organization of absorptive capacity. Industry \& Innovation, 18(6), 581-610.

Bogers, M., Zobel, A. K., Afuah, A., Almirall, E., Brunswicker, S., Dahlander, L., Frederiksen, L., Gawer, A., Gruber, M., Haefliger, S., Hagedoorn, J., Hilgers, D., Laursen, K., Magnusson, M. G., Majchrzak, A., McCarthy, I. P., Moeslein, K. M., Nambisan, S., Piller, F. T., Radziwon, A., Rossi-Lamastra, C., Sims, J., \& ter Wal, A. L. J. (2017). The open innovation research landscape: established perspectives and emerging themes across different levels of analysis. Industry and Innovation, 24(1), 8-40.

Carmeli, A., Meitar, R., \& Weisberg, J. (2006). Self-leadership skills and innovative behavior at work. International Journal of Manpower, 27(1), 75-90.

Cassiman, B., \& Veugelers, R. (2006). In search of complementarity in innovation strategy: internal $R \& D$ and external knowledge acquisition. Management Science, 52(1), 68-82.

Chesbrough, H., \& Bogers, M. (2014). Explicating open innovation: Clarifying an emerging paradigm for understanding innovation. In H. Chesbrough, W. Vanhaverbeke, \& J. West (Eds.), New frontiers in open innovation (pp. 3-28). Oxford: Oxford University Press.

Cirera, X., \& Maloney, W.F. (2017). The innovation paradox: Developing-country capabilities and the unrealized promise of technological catch-up. Washington, DC: World Bank Group.

Coff, R., \& Kryscynski, D. (2011). Drilling for micro-foundations of human capital-based competitive advantages. Journal of Management, 37(5), 1429-1443.

Cohen, W. M., \& Levinthal, D. A. (1990). Absorptive capacity: a new perspective on learning and innovation. Administrative Science Quarterly, 35(1), 128-152.

Countryeconomy (2019). Country comparison Vietnam versus South Korea, https://countryeconomy.com/countries/compare/vietnam/ south-korea. Accessed 29 Mar 2019.

Dahlander, L., O'Mahony, S., \& Gann, D. M. (2016). One foot in, one foot out: how does individuals' external search breadth affect innovation outcomes? Strategic Management Journal, 37(2), 280-302.

de Jong, J. P. J., \& den Hartog, D. N. (2010). Measuring innovative work behaviour. Creativity and Innovation Management, 19(1), 23-36.

Deshpandé, R., \& Farley, J. U. (2004). Organizational culture, market orientation, innovativeness, and firm performance: an international research odyssey. International Journal of Research in Marketing, 21(1), 3-22.

Dorenbosch, L., Van Engen, M. L., \& Verhagen, M. (2005). On-the-job innovation: the impact of job design and human resource 
management through production ownership. Creativity and Innovation Management, 14(2), 129-141.

Dougherty, D. (1992). Interpretive barriers to successful product innovation in large firms. Organization Science, 3(2), 179-202.

Du, J. S., Leten, B., \& Vanhaverbeke, W. (2014). Managing open innovation projects with science-based and market-based partners. Research Policy, 43(5), 828-840.

Eisenhardt, K. M., \& Schoonhoven, C. B. (1996). Resource-based view of strategic alliance formation: Strategic and social effects in entrepreneurial firms. Organization Science, 7(2), 136-150.

Enkel, E., Gassmann, O., \& Chesbrough, H. W. (2009). Open R\&D and open innovation: exploring the phenomenon. $R \& D$ Management, 39(4), 311-316.

Ettlie, J. E., \& Elsenbach, J. M. (2007). The changing role of R\&D gatekeepers. Research-Technology Management, 50(5), 59-66.

Faems, D., de Visser, M., Andries, P., \& van Looy, B. (2010). Technology alliance portfolios and financial performance: value-enhancing and cost-increasing effects of open innovation. Journal of Product Innovation Management, 27(6), 785-796.

Felin, T., Foss, N. J., \& Ployhart, R. E. (2015). The microfoundations movement in strategy and organization theory. Academy of Management Annals, 9(1), 575-632.

Foss, N. J., Laursen, K., \& Pedersen, T. (2011). Linking customer interaction and innovation: the mediating role of new organizational practices. Organization Science, 22(4), 980-999.

Frank, B., \& Enkawa, T. (2008). How economic growth affects customer satisfaction. Asia Pacific Management Review, 13(2), 531-544.

Frank, B., Enkawa, T., \& Schvaneveldt, S. J. (2014a). How do the success factors driving repurchase intent differ between male and female customers? Journal of the Academy of Marketing Science, 42(2), 171-185.

Frank, B., Herbas Torrico, B., Enkawa, T., \& Schvaneveldt, S. J. (2014b). Affect vs. cognition in the chain from perceived quality to customer loyalty: the roles of product beliefs and experience. Journal of Retailing, 90(4), 567-586.

Fu, X., Li, J., Xiong, H., \& Chesbrough, H. (2014). Open innovation as a response to constraints and risks: evidence from China. Asian Economic Papers, 13(3), 30-58.

Grant, K. P., Baumgardner, C. R., \& Shane, G. S. (1997). The perceived importance of technical competence to project managers in the defense acquisition community. IEEE Transactions on Engneering Management, 44(1), 12-19.

Grewal, D., Puccinelli, N., \& Monroe, K. B. (2018). Meta-analysis: Integrating accumulated knowledge. Journal of the Academy of Marketing Science, 46(1), 9-30.

Guerrero, M., \& Urbano, D. (2017). The impact of Triple Helix agents on entrepreneurial innovations' performance: an inside look at enterprises located in an emerging economy. Technological Forecasting and Social Change, 119, 294-309.

Hair, J. F., Black, W. C., Babin, B. J., \& Anderson, R. E. (2010). Multivariate data analysis (7th ed.). Upper Saddle River: Pearson.

Hannah, S. T., \& Lester, P. B. (2009). A multilevel approach to building and leading learning organizations. The Leadership Quarterly, 20(1), 34-48.

Hansen, M. T. (1999). The search-transfer problem: the role of weak ties in sharing knowledge across organization subunits. Administrative Science Quarterly, 44(1), 82-111.

Henriksen, L. B. (2001). Knowledge management and engineering practices: the case of knowledge management, problem solving and engineering practices. Technovation, 21(9), 595-603.

Hertenstein, P., \& Williamson, P. J. (2018). The role of suppliers in enabling differing innovation strategies of competing multinationals from emerging and advanced economies: German and Chinese automotive firms compared. Technovation, 70, 46-58.

Hofstede, G. (1991). Cultures and organizations: Software of the mind. London: McGraw-Hill.
Howell, J. M. (2005). The right stuff: identifying and developing effective champions of innovation. Academy of Management Executive, 19(2), 108-119.

Hysong, S. J. (2008). The role of technical skill in perceptions of managerial performance. Journal of Management Development, 27(3), 275-290.

Ibarra, H. (1993). Network centrality, power, and innovation involvement: determinants of technical and administrative roles. Academy of Management Journal, 36(3), 471-501.

Kafouros, M. I., \& Forsans, N. (2012). The role of open innovation in emerging economies: do companies profit from the scientific knowledge of others? Journal of World Business, 47(3), 362-370.

Kanter, R. M. (1988). When a thousand flowers bloom: Structural, collective, and social conditions for innovation in organizations. In B. M. Staw \& L. L. Cummings (Eds.), Research in organizational behavior (Vol. 10, pp. 169-211). Greenwich: JAI Press.

Katila, R., \& Ahuja, G. (2002). Something old, something new: a longitudinal study of search behavior and new product introduction. Academy of Management Journal, 45(6), 1183-1194.

Katz, R., \& Allen, T. J. (1982). Investigating the not invented here (NIH) syndrome: a look at the performance, tenure, and communication patterns of $50 \mathrm{R} \& \mathrm{D}$ project groups. $R \& D$ Management, 12(1), 7-19.

Kozlenkova, I. V., Samaha, S. A., \& Palmatier, R. W. (2014). Resourcebased theory in marketing. Journal of the Academy of Marketing Science, 42(1), 1-21.

Kreft, I., \& de Leeuw, J. (1998). Introducing multilevel modeling. London: Sage.

Lam, S. K., Kraus, F., \& Ahearne, M. (2010). The diffusion of market orientation throughout the organization: a social learning theory perspective. Journal of Marketing, 74(5), 61-79.

Landini, F., \& Malerba, F. (2017). Public policy and catching up by developing countries in global industries: a simulation model. Cambridge Journal of Economics, 41(3), 927-960.

Laursen, K., \& Salter, A. J. (2006). Open for innovation: the role of openness in explaining innovation performance among U.K. manufacturing firms. Strategic Management Journal, 27(2), 131150.

Laursen, K., \& Salter, A. J. (2014). The paradox of openness: appropriability, external search and collaboration. Research Policy, 43(5), 867-878.

Lindell, M. K., \& Whitney, D. J. (2001). Accounting for common method variance in cross-sectional research designs. Journal of Applied Psychology, 86(1), 114-121.

Luo, Y., Sun, J., \& Wang, S. L. (2011). Emerging economy copycats: capability, environment, and strategy. Academy of Management Perspectives, 25(2), 37-56.

Malerba, F., \& Mani, S. (Eds.). (2009). Sectoral systems of innovation and production in developing countries: Actors, structure and evolution. Cheltenham: Edward Elgar Publishing.

Maxwell, G.C. (1989). Training and development of the technical manager. Paper presented at the IEEE 1989 National Aerospace and Electronics Conference, NAECON 1989, may 22-26, Dayton, OH.

Mendonça, S. (2009). Brave old world: accounting for "high-tech" knowledge in "low-tech" industries. Research Policy, 38(3), 470 482.

Menon, T., \& Pfeffer, J. (2003). Valuing internal vs. external knowledge: explaining the preference for outsiders. Management Science, 49(4), 497-513.

Mohr, J., \& Spekman, R. (1994). Characteristics of partnership success: partnership attributes, communication behavior, and conflict resolution techniques. Strategic Management Journal, 15(2), 135-152.

Mumford, M. D., \& Gustafson, S. B. (1988). Creativity syndrome: integration, application, and innovation. Psychological Bulletin, 103(1), $27-43$. 
Murray, F., \& O'Mahony, S. (2007). Exploring the foundations of cumulative innovation: implications for organization science. Organization Science, 18(6), 1006-1021.

Nagano, M. S., Stefanovitz, J. P., \& Vick, T. E. (2014). Innovation management processes, their internal organizational elements and contextual factors: an investigation in Brazil. Journal of Engineering and Technology Management, 33, 63-92.

O'Connell, D. J., McNeely, E., \& Hall, D. T. (2008). Unpacking personal adaptability at work. Journal of Leadership and Organizational Studies, 14(3), 248-259.

Parzefall, M.-R., Seeck, H., \& Leppänen, A. (2008). Employee innovativeness in organizations: a review of the antecedents. Finnish Journal of Business Economics, 2(8), 165-182.

Phelps, C. C. (2010). A longitudinal study of the influence of alliance network structure and composition on firm exploratory innovation. Academy of Management Journal, 53(4), 890-913.

Randhawa, K., Wilden, R., \& Hohberger, J. (2016). A bibliometric review of open innovation: setting a research agenda. Journal of Product Innovation Management, 33(6), 750-772.

Rangus, K., \& Černe, M. (2019). The impact of leadership influence tactics and employee openness toward others on innovation performance. $R \& D$ Management, 49(2), 168-179.

Rosenthal, R. (1991). Meta-analysis: a review. Psychosomatic Medicine, 53(3), 247-271.

Rust, R. T., Zahorik, A. J., \& Keiningham, T. L. (1995). Return on quality (ROQ): making service quality financially accountable. Journal of Marketing, 59(2), 58-70.

Rust, R. T., Lemon, K. N., \& Zeithaml, V. A. (2004). Return on marketing: using customer equity to focus marketing strategy. Journal of Marketing, 68(1), 109-127.

Safdar, U., Badir, Y. F., \& Afsar, B. (2017). Who can I ask? How psychological safety affects knowledge sourcing among new product development team members. The Journal of High Technology Management Research, 28(1), 79-92.

Salge, T. O., Farchi, T., Barrett, M. I., \& Dopson, S. (2013). When does search openness really matter? A contingency study of health-care innovation projects. Journal of Product Innovation Management, 30(4), 659-676.

Salter, A. J., Criscuolo, P., \& ter Wal, A. L. J. (2014). Coping with open innovation: responding to the challenges of external engagement in R\&D. California Management Review, 56(2), 77-94.

Salter, A. J., ter Wal, A. L. J., Criscuolo, P., \& Alexy, O. (2015). Open for ideation: individual-level openness and idea generation in R\&D. Journal of Product Innovation Management, 32(4), 488-504.

Schroder, H. M. (1989). Managerial competence: The key to excellence. Dubuque: Kendall Hunt.

Shalley, C. E., \& Gilson, L. L. (2004). What leaders need to know: a review of social and contextual factors that can foster or hinder creativity. The Leadership Quarterly, 15(1), 33-53.

Shih, H., \& Susanto, E. (2011). Is innovative behavior really good for the firm? Innovative work behavior, conflict with coworkers and turnover intention: moderating roles of perceived distributive fairness. International Journal of Conflict Management, 22(2), 111-130.

Singh, S. K., \& Gaur, S. S. (2018). Entrepreneurship and innovation management in emerging economies. Management Decision, $56(1), 2-5$

Slater, S. F. (1997). Developing a customer value-based theory of the firm. Journal of the Academy of Marketing Science, 25(2), 162-167.
Svetina, A. C., \& Prodan, I. (2008). How internal and external sources of knowledge contribute to firms' innovation performance. Managing Global Transitions, 6(3), 277-299.

Terjesen, S., \& Patel, P. C. (2017). In search of process innovations: the role of search depth, search breadth, and the industry environment. Journal of Management, 43(5), 1421-1446.

Tushman, M. L. (1977). Special boundary roles in the innovation process. Administrative Science Quarterly, 22(4), 587-605.

Tushman, M. L., \& Romanelli, E. (1983). Uncertainty, social location and influence in decision making: a sociometric analysis. Management Science, 29(1), 12-23.

van de Ven, A. H. (1986). Central problems in the management of innovation. Management Science, 32(5), 590-607.

Van Minh, N., Badir, Y. F., Quang, N. N., \& Afsar, B. (2017). The impact of leaders' technical competence on employees' innovation and learning. Journal of Engineering and Technology Management, 44, 44-57.

Vega-Jurado, J., Gutiérrez-Gracia, A., \& Fernández-de-Lucio, I. (2008). Analyzing the determinants of firm's absorptive capacity: beyond R\&D. R\&D Management, 38(4), 392-405.

von Hippel, E. (1988). The sources of innovation. New York: Oxford University Press.

West, J., \& Bogers, M. (2014). Leveraging external sources of innovation: a review of research on open innovation. Journal of Product Innovation Management, 31(4), 814-831.

Wimalachandra, D. C., Frank, B., \& Enkawa, T. (2014a). Leveraging customer orientation to build customer value in industrial relationships. Journal of Japanese Operations Management and Strategy, 4(2), 46-61.

Wimalachandra, D. C., Frank, B., \& Enkawa, T. (2014b). Strategic openness in quality control: adjusting NPD strategic orientation to optimize product quality. International Journal of Industrial Engineering, 21(6), 348-359.

Woodman, R. W., Sawyer, J. E., \& Griffin, R. W. (1993). Toward a theory of organizational creativity. Academy of Management Review, 18(2), 293-321.

Woodruff, R. B. (1997). Customer value: the next source for competitive advantage. Journal of the Academy of Marketing Science, 25(2), 139-153.

Wu, Y. C., Lin, B. W., \& Chen, C. J. (2013). How do internal openness and external openness affect innovation capabilities and firm performance? IEEE Transactions on Engineering Management, 60(4), 704-716.

Xie, Z., \& Li, J. (2018). Exporting and innovating among emerging market firms: the moderating role of institutional development. Journal of International Business Studies, 49(2), 222-245.

Zhang, X., \& Bartol, K. (2010). Linking empowering leadership and employee creativity: the influence of psychological empowerment, intrinsic motivation, and creative process engagement. Academy of Management Journal, 53(1), 107-128.

Publisher's note Springer Nature remains neutral with regard to jurisdictional claims in published maps and institutional affiliations. 